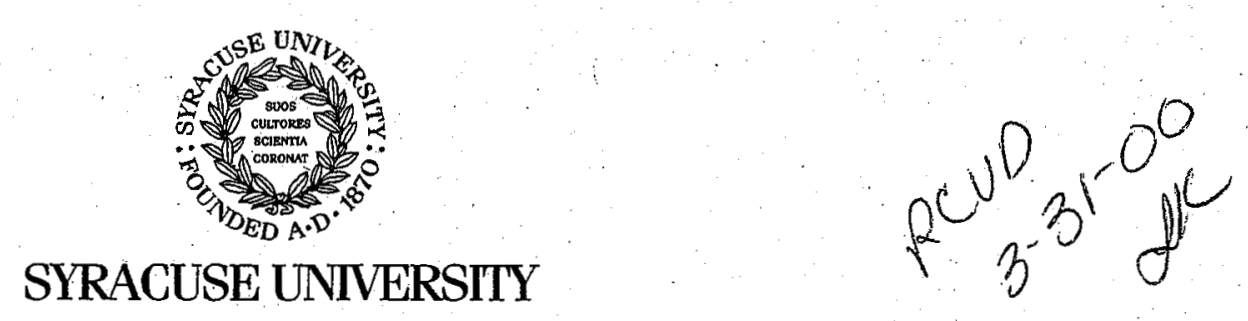

L.C. SMTTH COLLEGE OF ENGINEERING AND COMPUTER SCIENCE

DEPARTMENT OF CHEMIGAL ENGINEERING AND MATERIALS SCIENCE

March 27, 2000

Ms. Lisa Kuzniar
DOE/METC
M/S FO7
3610 Collins Ferry Road
Morgantown, WV 26507-0880

Dear Ms. Kuzniar:

Enclosed is a copy of our Final Report on DOE Grant, DE-FG21-91MC28072, "Upgrading Natural Gas via Membrane Separation Processes". We hope that you will find the report satisfactory.

We greatly appreciate your support of this project and your patience in waiting for this report.

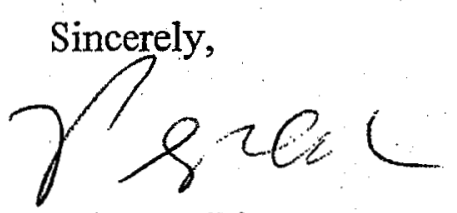

Philip A. Rice

Professor

PAR:rrd

Cc: Mary Ann Holmquist, Sponsored Programs
RFCFNFI FITS

JAN 292004 


\title{
UPGRADING NATURAL GAS VIA MEMBRANE SEPARATION PROCESSES
}

DE-FG21-91MC28072

\section{COMPREHENSIVE TECHNICAL REPORT}

\author{
by
}

S.A. Stern, P.A. Rice, and J. Hao

Dept. of Chemical Engineering and Materials Science

Syracuse University, Syracuse, NY 13244

Prepared for:

Federal Energy Technology Center

U.s. Department of Energy

Morgantown, WV

March 2000 


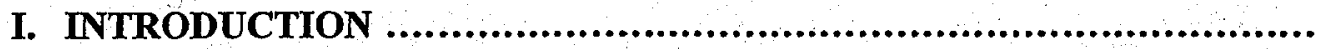

1. Objective of Study.

2. General Considerations .......................................................

II. MEMBRANE PROCESS DESIGN .......................................... 2

1. Operating Conditions and Economic Parameters ............................ 2

2. Membrane Process Configurations .............................................. 3

A. Membrane Process without Recycle ..................................... 3

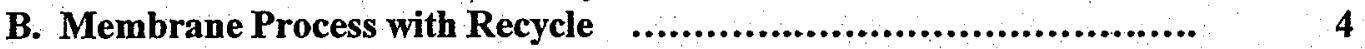

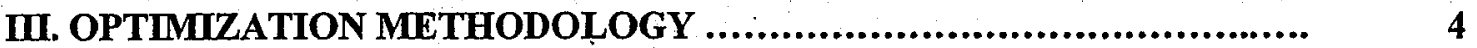

1. Problem Formulation and Analysis ......................................... 4

2. Optimization Methods $\quad$.......................................................... $\quad 5$

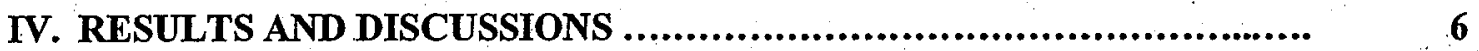

1. Membrane Process without Recycle ............................................ \% 6

A. Processing Costs for Base-Case Conditions ............................ 6

1). Single permeation stage with $\mathrm{H}_{2} \mathrm{~S}$-selective membranes............. 6

2). Single permeation stage with $\mathrm{CO}_{2}$-selective membranes ........... 7

3). Permeation stage(s) with $\mathrm{CO}_{2-}$ and $\mathrm{H}_{2} \mathrm{~S}$-selective membranes ..... 8

4). Adjustment of $\mathrm{CO}_{2}$ and $\mathrm{H}_{2} \mathrm{~S}$ concentrations in retentate ........... 10

5). Components of Total Processing Costs............................. $\quad 10$

B. Effects of Operating and Economic Parameters on Processing Cost .. 11

1). Effect of Flow Rate .................................................. 11

2). Effect of Wellhead Price of Natural Gas ............................. 11

3). Effect of Membrane Module Cost ...................................... 12

4). Effect of Feed Pressure .................................................. 12

2. Membrane Process with Recycle ............................................ 13

3. Comparison of Membrane Process with Adsorption ........................ 15

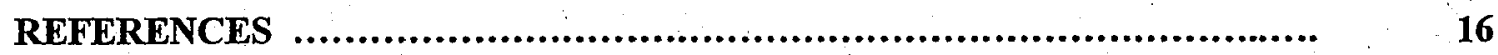

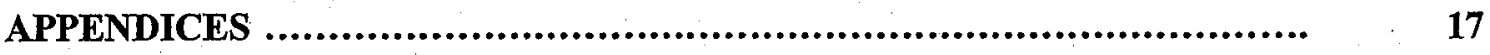

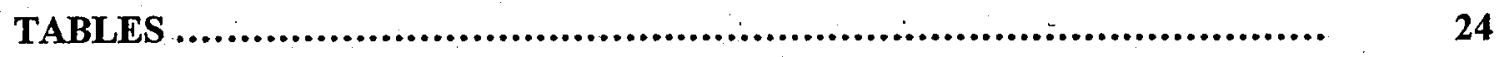

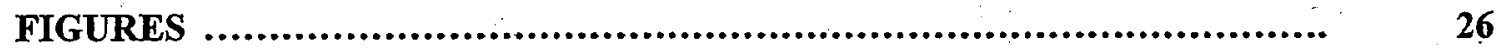




\section{MEMBRANE PROCESSES FOR THE UPGRADING OF LOW-QUALITY NATURAL GAS}

\section{INTRODUCTION}

\section{Objective of Study}

The objective of the present study is to assess the potential usefulness of membrane separation processes for removing $\mathrm{CO}_{2}$ and $\mathrm{H}_{2} \mathrm{~S}$ from low-quality natural gas containing substantial amounts of both these "acid" gases, e.g., up to 40 mole-\% $\mathrm{CO}_{2}$ and 10 mole- $\% \mathrm{H}_{2} \mathrm{~S}$. The membrane processes must be capable of upgrading the crude natural gas to pipeline specifications $\left(\leq 2 \mathrm{~mole}-\% \mathrm{CO}_{2}, \leq 4 \mathrm{ppm} \mathrm{H}_{2} \mathrm{~S}\right)$. Moreover, these processes must also be economically competitive with the conventional separation techniques, such as gas absorption, utilized for this purpose by the gas industry.

\section{General Considerations}

Natural gas is one of the three major energy resources in the United States together with oil and coal. The natural gas demand in 1995 was 22.25 quadrillion Btu, or about $25.5 \%$ of the total energy consumption and just below the demand for oil [1]. According to the Gas Research Institute (GRI) of Chicago, IL, the demand for natural gas will increase steadily and may reach $27 \%$ of the total energy consumption in 2015 [2].

Crude natural gas containing substantial amounts of $\mathrm{CO}_{2}$ (but only small amounts of $\mathrm{H}_{2} \mathrm{~S}$ ) is being increasingly upgraded to pipeline specifications by means of membrane separation processes [3-7]. These processes offer a number of important advantages over the conventional techniques of gas separation. Thus, membrane processes are inherently energy-efficient and, due to their modular design, can be easily scaled up or operated at reduced capacity. Moreover, these processes offer good space and weight efficiency and adjust readily to variations in feed gas composition and flow rate.

Membrane processes for the upgrading of natural gas are, in addition, environmentally safe and usually operate at ambient temperature, thereby avoiding the energy losses associated with heat exchange [7-10]: Also, membrane plants can be used to process natural gas at wellheads instead of at a central plant [7].

Until recently, large-scale membrane processes for the upgrading of natural gas utilized membranes made from cellulose acetate, which have a relatively modest $\mathrm{CO}_{2} / \mathrm{CH}_{4}$ selectivity, cf. ref. [11]. These processes are economically competitive only when used for the treatment of natural gas containing over $10-20$ mole- $\% \mathrm{CO}_{2}$, depending on the wellhead pressure. In the last few years new types of polyimide membranes with much higher $\mathrm{CO}_{2} / \mathrm{CH}_{4}$ selectivities and equal or larger permeabilities to $\mathrm{CO}_{2}$ were developed at Syracuse University [12] and elsewhere. The new membranes will substantially improve the economics of membrane processes for the upgrading of natural gas and extend their ranges of applications.

In view of the expected growth in the demand for natural gas, increasing attention is being devoted by the U.S. Department of Energy and by the gas industry to the upgrading of low-quality natural gas containing substantial amounts of both $\mathrm{H}_{2} \mathrm{~S}$ and $\mathrm{CO}_{2}$. 
Consequently, a membrane process that could economically reduce the concentrations of these "acid" gases to pipeline specifications will require polymer membranes that exhibit both high $\mathrm{H}_{2} \mathrm{~S} / \mathrm{CH}_{4}$ and $\mathrm{CO}_{2} / \mathrm{CH}_{4}$ selectivities. However, neither the cellulose acetate membranes nor the newly developed polyimide membranes exhibit a sufficiently high $\mathrm{H}_{2} \mathrm{~S} / \mathrm{CH}_{4}$ selectivity for this application. Recent studies have shown that certain polyurethane block polymers are very promising membrane materials for the removal of $\mathrm{H}_{2} \mathrm{~S}$ from natural gas. Thus, the $\mathrm{H}_{2} \mathrm{~S} / \mathrm{CH}_{4}$ selectivity of a poly(ether urethane urea) membrane synthesized at Syracuse University and designated hereafter as PU4 is about 4 times higher than that of cellulose acetate membranes [at $95^{\circ} \mathrm{F}\left(35^{\circ} \mathrm{C}\right)$ and 147 psia $(10.14$ bars)] [13]. Even more impressive is the fact that the permeability of the PU4 membranes to $\mathrm{H}_{2} \mathrm{~S}$ is 93 times higher than that of cellulose acetate membranes under the same conditions. However, the $\mathrm{CO}_{2} / \mathrm{CH}_{4}$ selectivity of PU4 membranes is relatively low.

The above results suggest that it may be possible to develop membrane processes for the upgrading of low-quality natural gas by utilizing both highly $\mathrm{CO}_{2}$-selective membranes, such as the new polyimide membranes mentioned above, and highly $\mathrm{H}_{2} \mathrm{~S}-$ selective membranes, such as the newly-developed PU4 membranes. Comprehensive membrane process simulations and economic evaluations have been completed in order to identify the process configurations that will most effectively combine the two types of membranes mentioned above. It is also important to determine if the pipeline specifications for $\mathrm{H}_{2} \mathrm{~S}$ and $\mathrm{CO}_{2}$ can be met by means of a simpler membrane process utilizing only the highly $\mathrm{H}_{2} \mathrm{~S}$-selective PU4 membranes, at least for some ranges of acid gas concentrations in natural gas.

Both types of membranes considered in this study are much more permeable to $\mathrm{H}_{2} \mathrm{~S}$ and $\mathrm{CO}_{2}$ than to $\mathrm{CH}_{4}$. Consequently, in the membrane processes under consideration the two acid gases will concentrate in the permeate (low-pressure) stream, whereas the $\mathrm{CH}_{4}$ will concentrate in the retentate (high-pressure) stream, i.e., in the fraction of natural gas (the "feed") not permeating through the membranes. Hence, the retentate is the desired product, i.e., the upgraded natural gas. These are very favorable process conditions because the retentate will be obtained at almost wellhead pressure. The main pressure loss in the retentate stream will be caused by the pressure drop inside the membrane modules, which is generally very small compared to the pressure drop across the membranes.

\section{MEMBRANE PROCESS DESIGN}

\section{Operating Conditions and Economic Parameters}

Computer simulations and economic assessments of membrane separation processes for the upgrading of low-quality natural gas were performed for natural gas "feeds" containing up to 40 mole- $\% \mathrm{CO}_{2}$ as well as up to $10 \mathrm{~mole}-\% \mathrm{H}_{2} \mathrm{~S}$, the balance being $\mathrm{CH}_{4}$. It is assumed that in all cases the concentrations of $\mathrm{CO}_{2}$ and $\mathrm{H}_{2} \mathrm{~S}$ in the retentate stream (the desired product) will meet pipeline specifications. It should be noted that the pipeline specifications for $\mathrm{H}_{2} \mathrm{~S}$ are much more stringent than those for $\mathrm{CO}_{2}\left(\leq 4 \mathrm{ppm} \mathrm{H}_{2} \mathrm{~S}, \leq 2\right.$ mole- $\left.\% \mathrm{CO}_{2}\right)$.

The separation performance of eight different membrane process configurations without or with recycle, and utilizing either $\mathrm{CO}_{2}-$ or $\mathrm{H}_{2} \mathrm{~S}$-selective membranes or both, 
has been investigated [15]. The process configurations are described in a following section.

The assumed operating conditions (the "base-case" conditions) are typical for a medium-sized acid gas removal plant with a feed flow rate of 35 MMSCFD. The feed pressure was taken to be 800 psia ( 55.14 bars) and the permeate pressure as 20 psia (1.38 bars). Other assumed operating conditions and the selected economic parameters are listed in Tables 1-3.

The $\mathrm{CH}_{4}, \mathrm{CO}_{2}$, and $\mathrm{H}_{2} \mathrm{~S}$ concentrations in the retentate and permeate product streams will depend on the selectivities of the membranes to these gases, on the feed composition, and on the selected operating conditions. The effects of varying feed flow rate, feed pressure, membrane module cost, and price of $\mathrm{CH}_{4}$ on the process economics have also been examined in a "sensitivity" study.

It should be noted that polymer membranes are only partially selective to gases. As a result, some $\mathrm{CH}_{4}$ in the feed stream will permeate through the membranes together with the $\mathrm{CO}_{2}$ and $\mathrm{H}_{2} \mathrm{~S}$, and consequently will be lost (unless otherwise recovered). Hence, the cost of the $\mathrm{CH}_{4}$ lost in the permeate must be included in the processing cost of crude natural gas.

\section{Membrane Process Configurations}

In the following discussion a "membrane process configuration" is taken to consist of a single permeation stage or of two permeation stages connected in series or cascade. The "permeation stage" is the basic membrane separation unit and consists, in turn, of a single membrane module or of two or more modules connected in parallel, depending on the feed flow rate and module size.

The membrane process configurations may or may not be provided with recycle streams, depending on the desired objective. For example, recycle streams may be used to reduce the loss of a valuable feed component, such as $\mathrm{CH}_{4}$, in the permeate.

In the present study it is assumed that the membrane modules are of the "spiralwound" type and utilize "composite" membrane in sheet form, with an effective thickness of $1,000 \AA\left(3.93 \times 10^{-3} \mathrm{mil}\right)[3,7,9,10]$. Consequently, the cost of membrane modules for the "base-case" conditions was taken to be that of spiral-wound modules, cf. Table 3.

The membranes considered for use are, as mentioned above, some of the highly $\mathrm{CO}_{2}$-selective, fluorine-containing polyimide membranes [12] and the highly $\mathrm{H}_{2} \mathrm{~S}$ selective poly(ether urethane urea) PU4 membranes [13].

\section{A. Membrane Processes without Recycle}

Five different membrane process configurations without recycle streams have been examined and optimized by computer simulations. These process configurations are illustrated in Figures 1-5 and comprise:

1) A single membrane permeation stage utilizing only the highly $\mathrm{H}_{2} \mathrm{~S}$-selective membranes, cf. Figure 1;

2) $A$ single membrane permeation stage utilizing only the highly $\mathrm{CO}_{2}$-selective membranes, cf., Figure 2 ;

3) $A$ single membrane permeation stage utilizing both the $\mathrm{H}_{2} \mathrm{~S}$-selective and $\mathrm{CO}_{2}-$ selective membranes, cf., Figure 3; 
4) Two membrane permeation stages connected in series, the first stage utilizing only the $\mathrm{H}_{2} \mathrm{~S}$-selective membranes and the second stage only the $\mathrm{CO}_{2}$-selective membranes, cf., Figure 4 ; and

5) Two membrane permeation stages connected in series, the first stage utilizing only the $\mathrm{CO}_{2}$-selective membranes and the second stage only the $\mathrm{H}_{2} \mathrm{~S}$-selective membranes, cf., Figure 5.

The ratio of areas of the $\mathrm{CO}_{2}-$ and $\mathrm{H}_{2} \mathrm{~S}$-selective membranes required in the last three process configurations will depend on the relative concentrations of the two acid gases in the natural gas feed and on the selected operating conditions.

\section{B. Membrane Processes with Recycle}

Three membrane process configurations with recycle have been simulated and optimized in a preliminary way via a computer program. The three membrane process configurations that have been partially studied are:

1) Two permeation stages in cascade with recycle, both stages utilizing only the $\mathrm{H}_{2} \mathrm{~S}$-selective membranes, cf., Figure 6;

2) Two permeation stages in cascade with recycle, the first stage utilizing only the $\mathrm{H}_{2} \mathrm{~S}$-selective membranes and the second stage only the $\mathrm{CO}_{2}$-selective membranes, $\mathrm{cf}$., Figure 7;

3) Two permeation stages in cascade with recycle, both stages utilizing only the $\mathrm{CO}_{2}$-selective membranes, cf., Figure 8 .

\section{III.OPTIMIZATION METHODOLOGY}

The mathematical derivation and the theoretical background for the single permeation stage with one selective membrane $\left(\mathrm{H}_{2} \mathrm{~S}\right.$-selective or $\mathrm{CO}_{2}$-selective) and for the single permeation stage with both $\mathrm{H}_{2} \mathrm{~S}$ - and $\mathrm{CO}_{2}$-selective membranes are given in the Appendix I. The membrane configuration of two stages in series or cascade (Figures 4 to 8 ) is just two single-permeation stages connected in series or cascade and its mathematical derivation for each stage is similar to that of the single stage. Therefore the mathematical derivation of two stages in series or cascade (Figures 4 to 8 ) is not presented in here.

\section{Problem Formulation and Analysis}

The operating conditions in all membrane process configurations studied were optimized so as to yield the lowest processing costs, i.e., the lowest cost of upgrading the crude natural gas to pipeline specifications. In view of the complex nature of the membrane process design involved, several different optimization methods were employed for this purpose.

The objective function in the present process design study is the processing cost and the optimization constraints are the product purity. The objective function and constraints can be expressed as follows:

Objective function:

$$
\begin{aligned}
& \text { Processing cost, } f(\theta 1, \ldots \theta i, \ldots \theta n, \quad \beta 1, \ldots \beta i, \ldots \beta n), \\
& 1_{\leq i \leq n ;} \quad 0 \leq \theta i \leq 1 ; \quad 0 \leq \beta i \leq 1 ;
\end{aligned}
$$


where the decision variable $\theta i$ is the stage-cut in stage $i$, and the decision variable $\beta i$ is the area-fraction of the $\mathrm{H}_{2} \mathrm{~S}$-selective membrane in stage $i$, i.e., the ratio Area ${ }_{\mathrm{H} 2 \mathrm{~S}} /\left(\mathrm{Area}_{\mathrm{H} 2 \mathrm{~S}}\right.$ $\left.+\mathrm{Area}_{\mathrm{CO} 2}\right)$. The terms "Area $\mathrm{HzS}$ " and "Area $\mathrm{CO}_{2}$ " designate the areas of the $\mathrm{H}_{2} \mathrm{~S}-$ and $\mathrm{CO}_{2}$ selective membranes, respectively, in a permeation stage. The "stage-cut" is the fraction of feed allowed to permeate through the membrane in a given permeation stage, i.e., the ratio of permeate-to-feed flow rates. It should be noted that if stage $i$ contains only one type of selective membrane, $\beta i$ has the limiting value of either 0 (if the membrane is $\mathrm{CO}_{2}$-selective) or of 1 (if the membrane is $\mathrm{H}_{2} \mathrm{~S}$-selective).

Constraints:

Pipeline specification for $\mathrm{CO}_{2}: x_{\mathrm{CO}} \leq 2$ mole- $\%$

Pipeline specification for $\mathrm{H}_{2} \mathrm{~S}: x_{H 2 S} \leq 4 \mathrm{ppm}$

These constraints are implicit and cannot be expressed in terms of the decision variables $\theta i$ and $\beta i$. The objective function for the processing cost, $f(\theta 1, \ldots \theta i, \ldots \theta n, \beta 1$, $\ldots \beta i, \ldots \beta n)$, is also implicit and dependent on the membrane process configuration and feed composition. No unique and explicit expression is available for the processing cost. Moreover, the number of variables $(\theta$ and $\beta$ ) to be optimized is determined by the selected membrane process configuration.

For a given feed composition, the objective of the present study is to find not only the optimum values of the decision variables for a specified process configuration but also the optimum configuration. Therefore, the optimization procedure is a two-step problem. For any given feed composition, each process configuration has a set of

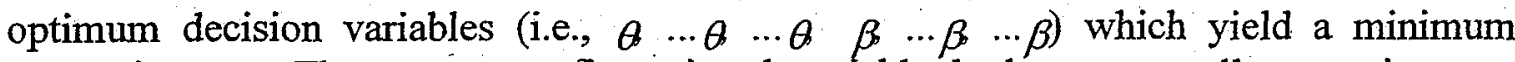
processing cost. The process configuration that yields the lowest overall processing cost for that feed composition can then be determined by comparing the processing costs for all the optimized process configurations studied.

\section{Optimization Methods}

For a single permeation stage incorporating only $\mathrm{CO}_{2^{-}}$or $\mathrm{H}_{2} \mathrm{~S}$-selective membranes, only one decision variable needs to be optimized, namely, the stage-cut $\theta$ In this case, it is possible to use any of the classic optimization methods (e.g., region elimination, quadratic estimation, etc.) to find the optimum value of è. However, it was found that the processing cost increases with an increase in the stage-cut $\theta$ Therefore, for the single-stage configuration with a single type of selective membrane, the optimum decision variable $\theta$ is the minimum stage-cut that can produce pipeline-quality natural gas, that is, the stage cut where either one or both constraints are active. (Here active means the sign of the constraint is equal. For example, for the constraint $x_{\mathrm{CO}} \leq 2 \mathrm{~mole}-$ $\%$, if $x_{\mathrm{CO} 2}=2$ mole- $\%$ in the product, the constraint is active; if $x_{\mathrm{CO} 2}<2 \mathrm{~mole}-\%$ in the product, the constraint is inactive.) It is advantageous to use the desired product purity as a criterion for finding the optimum stage cut $\theta$

Reference is now made to the membrane configurations shown in Figure 3 ( $a$ single stage utilizing both $\mathrm{H}_{2} \mathrm{~S}$ - and $\mathrm{CO}_{2}$-selective membranes) and in Figures 4 - 8 (two stages connected in series or cascade, each stage utilizing only one type of selective membranes), cf., Section II.2. Only two decision variables need to be optimized for these 
configurations, namely, $\theta \quad \beta$ for the configuration of Figure 3, and $\theta 1, \theta 2$ for the configurations of Figures 4 to 8 . The two-variable optimization problem can be reduced two one-variable problems. Then any of one-variable optimization method for the single stage with one selective membrane can be used to find the optimum decision variables ( $\theta$ and $\beta$ or $\dot{\theta}_{1}$ and $\theta 2$ ). The one-variable optimization method used in this study is the Golden Section method [14], which is one of the most effective region-elimination methods for the unimodal problems. An example of this method is presented in Appendix II.

\section{RESULTS AND DISCUSSIONS}

\section{Membrane Processes without Recycle}

\section{A. Processing Costs for Base-Case Conditions}

1). Single Permeation Stage with $\mathrm{H}_{2} \mathrm{~S}$-Selective Membranes

The total processing cost of crude natural gas consists of three parts: (a) the capital-related, or investment, cost (CRC), (b) the variable operating and maintenance cost (VOM), and (c) the cost of $\mathrm{CH}_{4}$ lost in the permeate stream (CH4LS). The processing cost is reported in this study as the cost per MSCF (1,000 standard cubic feet) of product, i.e., of natural gas upgraded to pipeline specifications $\left(\leq 2 \mathrm{~mole}-\% \mathrm{CO}_{2}\right.$ and $\leq$ 4 ppm $\mathrm{H}_{2} \mathrm{~S}$ ).

The dependence of the processing costs on the concentration of $\mathrm{CO}_{2}$ in the crude natural gas feed $\left(0-40\right.$ mole- $\left.\% \mathrm{CO}_{2}\right)$ is illustrated in Figure 9 for a constant concentration of $1 \mathrm{~mole}-\% \mathrm{H}_{2} \mathrm{~S}$ in the feed. The data in this figure were obtained for the process design configuration shown in Figure 1, namely, a single permeation stage utilizing only the highly $\mathrm{H}_{2} \mathrm{~S}$-selective poly(ether urethane urea) PU4 membranes.

The plot in Figure 9 shows that, for a constant $\mathrm{H}_{2} \mathrm{~S}$ concentration in the feed stream, the processing cost first decreases, reaches a minimum, and finally increases with increasing $\mathrm{CO}_{2}$ concentration in the feed. The minimum results from the intersection of two curves denoted $\mathrm{A}$ and $\mathrm{B}$. The two curves represent the costs of membrane processes that will reduce the $\mathrm{CO}_{2}$ and $\mathrm{H}_{2} \mathrm{~S}$ concentrations in the retentate stream to the following levels:

(a) At all $\mathrm{CO}_{2}$ concentrations in the feed lower than that at the intersection point, i.e., along curve $A$, the retentate will contain a constant amount of $4 \mathrm{ppm} \mathrm{H}_{2} \mathrm{~S}$, which is the pipeline specification for $\mathrm{H}_{2} \mathrm{~S}$, and $<2$ mole- $\% \mathrm{CO}_{2}$, which is less than the pipeline specification for this gas. As the $\mathrm{CO}_{2}$ concentration in the feed increases (and, therefore, that of $\mathrm{CH}_{4}$ decreases), the concentration of $\mathrm{CO}_{2}$ in the retentate also increases, but remains below 2 mole-\%.

The processing cost decreases under these conditions because of the decrease in the $\mathrm{CH}_{4}$ losses in the permeate (per MSCF of product gas). Also, the increase in the partial pressure of $\mathrm{CO}_{2}$ caused by the increasing concentration of this gas in the feed, and the corresponding increase in the driving force of $\mathrm{CO}_{2}$ across the membrane, results in a decrease in the required membrane area, and therefore in the capital investment cost of the process. 
The processing costs for the conditions represented by curve $A$ are controlled by the cost of $\mathrm{H}_{2} \mathrm{~S}$ removal, i.e., the cost of reducing the concentration of $\mathrm{H}_{2} \mathrm{~S}$ to $4 \mathrm{ppm}$ and maintaining it constant at this concentration;

(b) At the minimum of the plot in Figure 9, i.e., at the intersection of curves A and $\mathrm{B}$, the concentrations of both $\mathrm{CO}_{2}$ and $\mathrm{H}_{2} \mathrm{~S}$ in the retentate have just reached their pipeline specifications of 2 mole- $\%$ and $4 \mathrm{ppm}$, respectively;

(c) At all $\mathrm{CO}_{2}$ concentrations in the feed higher than that at the above-mentioned intersection, i.e., along curve $\mathrm{B}$, the retentate (the desired product) will contain a constant amount of 2 mole- $\% \mathrm{CO}_{2}$, which is the pipeline specification for $\mathrm{CO}_{2}$, and $<4 \mathrm{ppm} \mathrm{H}_{2} \mathrm{~S}$, which is less than the specification for $\mathrm{H}_{2} \mathrm{~S}$. As the $\mathrm{CO}_{2}$ concentration in the feed stream increases, the concentration of $\mathrm{H}_{2} \mathrm{~S}$ in the retentate further decreases below $4 \mathrm{ppm}$.

The processing cost increases in this case with increasing $\mathrm{CO}_{2}$ concentration in the feed because of an increase in both the $\mathrm{CH}_{4}$ losses in the permeate and in the membrane area required to maintain the $\mathrm{CO}_{2}$ concentration in the retentate stream at 2 mole-\%. The increase in membrane area exceeds the savings in membrane area resulting from the increase in the partial pressure of $\mathrm{CO}_{2}$ and in the driving force of this gas across the membranes.

The processing costs for the conditions represented by curve $B$ are controlled by the cost of $\mathrm{CO}_{2}$ removal, i.e., the cost of reducing the concentration of $\mathrm{CO}_{2}$ to 2 mole-\% and maintaining it constant at this concentration.

The dashed extensions of curves $\mathrm{A}$ and $\mathrm{B}$ below their intersection represent conditions where the concentration of either $\mathrm{CO}_{2}$ or of $\mathrm{H}_{2} \mathrm{~S}$ does not meet pipeline specifications.

The processing costs shown in Figure 9 are limited to natural gas feeds containing $0-40$ mole- $\% \mathrm{CO}_{2}$ but only 1 mole- $\% \mathrm{H}_{2} \mathrm{~S}$. When other $\mathrm{H}_{2} \mathrm{~S}$ concentrations in the feed are considered, the plots representing the processing cost versus the $\mathrm{CO}_{2}$ concentration in the feed remain similar in shape to those in Figure 9. However, at higher $\mathrm{H}_{2} \mathrm{~S}$ concentrations in the feed, the intersection in these plots is shifted toward higher $\mathrm{CO}_{2}$ concentrations and higher processing costs.

This behavior is illustrated in Figure 10, which is a three dimensional plot of the processing costs versus the $\mathrm{CO}_{2}$ and $\mathrm{H}_{2} \mathrm{~S}$ concentrations in the feed $\left(0-40\right.$ mole- $\% \mathrm{CO}_{2}$ and $1 \mathrm{ppm}-10$ mole- $\% \mathrm{H}_{2} \mathrm{~S}$ ). The solid curve which connects all the intersection points of the processing costs corresponds to the product stream containing 2 mole- $\% \mathrm{CO}_{2}$ and 4 ppm $\mathrm{H}_{2} \mathrm{~S}$. At any given $\mathrm{H}_{2} \mathrm{~S}$ concentration, if $\mathrm{CO}_{2}$ concentrations in the feed are lower than those at the intersection points, the processing cost is controlled by the $\mathrm{H}_{2} \mathrm{~S}$ removal; if $\mathrm{CO}_{2}$ concentrations in the feed are higher than those at the intersection points, the processing cost is controlled by the $\mathrm{CO}_{2}$ removal.

2). Single Permeation Stage with $\mathrm{CO}_{2}$-Selective Membranes

Figure 11 exhibits the processing costs obtained with a single permeation stage with $\mathrm{CO}_{2}$-selective membranes only (cf., Figure 2) as a function of $\mathrm{H}_{2} \mathrm{~S}$ in the crude natural gas feed $\left(1 \mathrm{ppm}\right.$ to 10 mole- $\left.\% \mathrm{H}_{2} \mathrm{~S}\right)$ at 20 mole- $\% \mathrm{CO}_{2}$. The processing cost first increases slowly, then reaches an intersection point, and finally increases rapidly with increasing $\mathrm{H}_{2} \mathrm{~S}$ concentration in the feed. Similar to Figure 9, the dashed extensions of curves $\mathrm{A}$ and $\mathrm{B}$ below their intersection represent conditions where the pipeline specification for either $\mathrm{H}_{2} \mathrm{~S}$ or $\mathrm{CO}_{2}$ is not met. However, the retentate (the desired 
product) compositions on curves $A$ and $B$ are different from those in Figure 6 and can be explained as following:

(a) At all $\mathrm{H}_{2} \mathrm{~S}$ concentrations in the feed lower than those at the intersection of curves $A$ and $B$, i.e., along curve $A$, the product stream will contain 2 mole- $\% \mathrm{CO}_{2}$ and $<$ $4 \mathrm{ppm} \mathrm{H}_{2} \mathrm{~S}$. The processing cost remains nearly constant with increasing $\mathrm{H}_{2} \mathrm{~S}$ concentration in the feed. This is due to the fact that the separation is controlled by the $\mathrm{CO}_{2}$ removal and the $\mathrm{CO}_{2}$ concentration in the feed is constant. Furthermore, the increase of the $\mathrm{H}_{2} \mathrm{~S}$ concentration in this region is quite small (less than $7 \mathrm{ppm}$ ), therefore it has little effect on the $\mathrm{CH}_{4}$. concentration in the feed (the balance of $\mathrm{CO}_{2}$ and $\mathrm{H}_{2} \mathrm{~S}$ ) and the change of the $\mathrm{CH}_{4}$ lost in the permeate is negligible; ppm $\mathrm{H}_{2} \mathrm{~S}$;

(b) At the intersection, the product stream contains exactly 2 mole- $\% \mathrm{CO}_{2}$ and 4

(c) At all $\mathrm{H}_{2} \mathrm{~S}$ concentrations in the feed higher than those at the intersection point, i.e., along curve $\mathrm{B}$, the product stream will contain $4 \mathrm{ppm} \mathrm{H}_{2} \mathrm{~S}$ and $<2$ mole- $\% \mathrm{CO}_{2}$ and the separation is controlled by the $\mathrm{H}_{2} \mathrm{~S}$ removal. The processing cost increases rapidly with the increase of $\mathrm{H}_{2} \mathrm{~S}$ concentration in the feed. This is because even the most highly $\mathrm{CO}_{2}$-selective membranes have a much lower $\mathrm{H}_{2} \mathrm{~S} / \mathrm{CH}_{4}$ selectivity than the highly $\mathrm{H}_{2} \mathrm{~S}$ selective poly(ether urethane urea) PU4 membranes considered in this study. As a result; considerably more $\mathrm{CH}_{4}$ is lost with a process configuration utilizing only $\mathrm{CO}_{2}$-selective membranes than with one utilizing only the $\mathrm{H}_{2} \mathrm{~S}$-selective membranes or both $\mathrm{CO}_{2}$ - and $\mathrm{H}_{2} \mathrm{~S}$-selective membranes. Moreover, the permeability to $\mathrm{H}_{2} \mathrm{~S}$ of the $\mathrm{CO}_{2}$-selective membranes is about $1 / 100$ th of that of the $\mathrm{H}_{2} \mathrm{~S}$-selective membranes. Therefore, the membrane area required to meet pipeline specifications with a process configuration utilizing only the $\mathrm{CO}_{2}$-selective membranes is commensurately larger.

Figure 12 is a three dimensional plot of the processing costs versus the $\mathrm{CO}_{2}$ and $\mathrm{H}_{2} \mathrm{~S}$ concentrations in the feed $\left(0-40\right.$ mole- $\% \mathrm{CO}_{2}$ and $\left.1 \mathrm{ppm}-10 \mathrm{~mole}-\% \mathrm{H}_{2} \mathrm{~S}\right)$. The solid curve which connects all the intersection points corresponds to the product stream containing 2 mole- $\% \mathrm{CO}_{2}$ and $4 \mathrm{ppm} \mathrm{H}_{2} \mathrm{~S}$. At any given $\mathrm{CO}_{2}$ concentration, if the $\mathrm{H}_{2} \mathrm{~S}$ concentrations in the feed are lower than those at the intersection points, the processing cost is controlled by the $\mathrm{CO}_{2}$ removal; if the $\mathrm{H}_{2} \mathrm{~S}$ concentrations in the feed are higher than those at the intersection points, the processing cost is controlled by the $\mathrm{H}_{2} \mathrm{~S}$ removal.

3). Permeation Stage(s) with both $\mathrm{CO}_{2}$ - and $\mathrm{H}_{2} \mathrm{~S}$ - Selective Membranes

As discussed in Section II.2.A, three different membrane process configurations utilizing both $\mathrm{CO}_{2}$ - and $\mathrm{H}_{2} \mathrm{~S}$-selective membranes have been considered in this study, $\mathrm{cf}$,, Figures 3, 4, and 5. The processing costs obtained with these configurations for the "base-case" conditions are compared in Figure 13 with those for the single-stage process configuration utilizing the $\mathrm{H}_{2} \mathrm{~S}$-selective membranes only. The comparison is made for a range of $\mathrm{CO}_{2}$ concentrations in the feed from 0 to 40 mole- $\%$ and an $\mathrm{H}_{2} \mathrm{~S}$ concentration in the feed of 1 mole-\%.

The plot shown in Figure 13 by a full heavy line is identical with that in Figure 9. It is seen that at $\mathrm{CO}_{2}$ concentrations lower than the one at the minimum of the plot, i.e., along curve $\mathrm{A}$, the processing costs are the same for all membrane process configurations utilizing $\mathrm{H}_{2} \mathrm{~S}$-selective membranes singly or in conjunction with $\mathrm{CO}_{2}-$ selective membranes, cf., Figures 1,3-5. This is because, for the conditions represented by curve $A$, the processing costs are controlled entirely by the cost of reducing the $\mathrm{H}_{2} \mathrm{~S}$ 
concentration in the retentate to $4 \mathrm{ppm}$. As a result, the processing costs are minimized only when the area of the $\mathrm{CO}_{2}$-selective membranes is reduced to zero. The process configurations utilizing both $\mathrm{CO}_{2}$ - and $\mathrm{H}_{2} \mathrm{~S}$-selective membranes are thus reduced to the single-stage configuration with $\mathrm{H}_{2} \mathrm{~S}$-selective membranes, which is the optimum configuration for these conditions.

By contrast, at $\mathrm{CO}_{2}$ concentrations in the feed higher than those at the minimum of the plot each of the membrane process configurations studied yields different processing costs, which are represented by curves B and C. Under these conditions the processing costs are controlled by:

(a) For the process configuration utilizing only the $\mathrm{H}_{2} \mathrm{~S}$-selective membranes: the cost of reducing the $\mathrm{CO}_{2}$ concentration in the retentate to 2 mole- $\%$, cf., curve $\mathrm{B}$ and Figure 1. It should be noted that in this case the concentration of $\mathrm{H}_{2} \mathrm{~S}$ will be reduced to less than $4 \mathrm{ppm}$;

(b) For the process configurations utilizing both the $\mathrm{CO}_{2}$ - and $\mathrm{H}_{2} \mathrm{~S}$-selective membranes: the cost of reducing the $\mathrm{CO}_{2}$ and $\mathrm{H}_{2} \mathrm{~S}$ concentrations to 2 mole- $\%$ and $4 \mathrm{ppm}$, respectively, cf., curves $\mathrm{C}$ and Figures 3-5.

The processing costs for the membrane process configurations incorporating $\mathrm{CO}_{2}$-selective membranes as well as $\mathrm{H}_{2} \mathrm{~S}$-selective membranes (curves $\mathrm{C}$ ) are all lower than the costs incurred with the process configuration utilizing only the latter membranes (curve B). The lowest processing costs of natural gas containing a higher concentration of $\mathrm{CO}_{2}$ in the feed than that at the minimum of the plot in Figure 13 is obtained with a process configuration consisting of two permeation stages in series, the first stage utilizing only the $\mathrm{H}_{2} \mathrm{~S}$-selective membranes and the second stage utilizing only the $\mathrm{CO}_{2}$ selective membranes, cf., Figure 4.

Figure 14 shows the fraction of $\mathrm{CH}_{4}$ recovered in the product stream as a function of $\mathrm{CO}_{2}$ concentrations in the feed from 0 to 40 mole- $\%$ and an $\mathrm{H}_{2} \mathrm{~S}$ concentration in the feed of 1 mole-\%. The membrane configuration of Figure 4 (two permeation stages in series, the first stage utilizing only the $\mathrm{H}_{2} \mathrm{~S}$-selective membranes and the second stage utilizing only the $\mathrm{CO}_{2}$-selective membranes) has the highest fraction of $\mathrm{CH}_{4}$ recovered in the product. Since the processing cost is dominated by the cost of $\mathrm{CH}_{4}$ lost in the permeate stream (to be discussed at Section IV.5), the membrane configuration of Figure 4 has the lowest processing cost (cf. Figure 13).

Our objective is to find the optimum membrane configurations at different feed concentrations. The processing costs shown in Figure 13 are limited to natural gas feeds containing $0-40$ mole- $\% \mathrm{CO}_{2}$ but only 1 mole- $\% \mathrm{H}_{2} \mathrm{~S}$. For the crude natural gas containing 0-40 mole- $\% \mathrm{CO}_{2}$ and $1 \mathrm{ppm}-10$ mole- $\% \mathrm{H}_{2} \mathrm{~S}$, the processing costs for the optimum membrane configuration are presented in Figure 15. At any given $\mathrm{H}_{2} \mathrm{~S}$ concentration, if $\mathrm{CO}_{2}$ concentrations in the feed are lower than those at the intersection points of the single stage with $\mathrm{H}_{2} \mathrm{~S}$-selective membranes (cf. Figure 10), the lowest processing costs are obtained, as mentioned before, with a single permeation stage provided with $\mathrm{H}_{2} \mathrm{~S}$-selective membranes only. At any given $\mathrm{CO}_{2}$ concentration, if $\mathrm{H}_{2} \mathrm{~S}$ concentrations in the feed are lower than those at the intersection points of the single stage with $\mathrm{CO}_{2}$-selective membranes (cf. Figure 12), the lowest processing costs are obtained for the membrane configuration of a single permeation stage provided with $\mathrm{CO}_{2}$-selective membranes only. For the feed concentrations between the intersection 
points of the single stage with $\mathrm{H}_{2} \mathrm{~S}$-selective membranes and the intersection points of the single stage with $\mathrm{CO}_{2}$-selective membranes, the optimum process configuration is that consisting of two permeation stages in series with $\mathrm{H}_{2} \mathrm{~S}$-selective membranes in the first stage and $\mathrm{CO}_{2}$-selective membranes in the second stage.

4). Adjustment of $\mathrm{CO}_{2}$ and $\mathrm{H}_{2} \mathrm{~S}$ Concentrations in Retentate

For a given feed flow rate, composition, and pressure, the desired $\mathrm{CO}_{2}$ and/or $\mathrm{H}_{2} \mathrm{~S}$ concentration in the retentate, e.g., $\leq 2$ mole- $\% \mathrm{CO}_{2}$ and $\leq 4 \mathrm{ppm} \mathrm{H}_{2} \mathrm{~S}$, is obtained as follows:

(a) For the single-stage configuration utilizing $\mathrm{H}_{2} \mathrm{~S}$-selective membranes only: by adjusting the "stage-cut", i.e., the fraction of feed which is allowed to permeate through the membranes. For a given feed flow rate and pressure, the desired stage-cut is obtained by adjusting the membrane area: an increase in membrane area will increase the stagecut.

In this case it is not possible to adjust the $\mathrm{CO}_{2}$ and $\mathrm{H}_{2} \mathrm{~S}$ concentrations in the retentate independently of one another. For example, under the conditions shown in Figure 9 , it is possible to reduce the $\mathrm{H}_{2} \mathrm{~S}$ concentration in the retentate to $4 \mathrm{ppm}$ by maintaining the $\mathrm{CO}_{2}$ concentration at $<2$ mole-\% (curve $\mathrm{A}$ ), or to reduce the $\mathrm{CO}_{2}$ concentration in the retentate to 2 mole- $\%$ by maintaining the $\mathrm{H}_{2} \mathrm{~S}$ concentration at $<4$ ppm (curve B). The actual concentration of $\mathrm{CO}_{2}$ in the former case and of $\mathrm{H}_{2} \mathrm{~S}$ in the latter case will depend on the feed compositions and the operating conditions used;

(b) For the two-stage configuration utilizing $\mathrm{H}_{2} \mathrm{~S}$-selective membranes in the first stage and $\mathrm{CO}_{2}$-selective membranes in the second stage: by adjusting the stage-cuts in the two stages. This can be achieved by adjusting the ratio of membrane areas in the two stages, i.e., the respective membrane areas.

In this case it is possible to adjust the $\mathrm{CO}_{2}$ and $\mathrm{H}_{2} \mathrm{~S}$ concentrations in the retentate independently of one another, for example, to obtain $2 \mathrm{~mole}-\% \mathrm{CO}_{2}$ and $4 \mathrm{ppm}_{2} \mathrm{~S}$ in the retentate. In all cases discussed above it is assumed that the permeate pressure is maintained constant.

5). Components of Total Processing Costs

It was mentioned above that the total processing costs consist of three main components, namely, capital-related, or investment, costs, variable operating and maintenance costs, and the cost of $\mathrm{CH}_{4}$ losses in the permeate. The relative magnitudes of these costs are given in Figure 16. This figure shows the lowest total processing costs and their components as a function of the $\mathrm{CO}_{2}$ concentration in the feed and for an $\mathrm{H}_{2} \mathrm{~S}$ concentration in the feed of 1 mole- $\%$. The costs on the left of the minima of the processing cost in the plots are for a single permeation stage utilizing only $\mathrm{H}_{2} \mathrm{~S}$-selective membranes. The costs on the right of the minima of the processing cost are for two permeation stages in series with $\mathrm{H}_{2} \mathrm{~S}$-selective membranes in the first stage and $\mathrm{CO}_{2}$ selective membranes in the second stage. All cost data are for the "base-case" conditions listed in Table 3.

Figure 16 shows that the $\mathrm{CH}_{4}$ losses in the permeate constitute by far the largest component of the total processing costs. The large $\mathrm{CH}_{4}$ losses are due to two factors: (a) The membrane configurations considered so far are all the configurations without recycle and therefore a significant amount of $\mathrm{CH}_{4}$ is lost in the permeate stream; (b) The gas permeability of the $\mathrm{H}_{2} \mathrm{~S}$-selective poly(ether urethane urea) PU4 membranes considered 
for use (PU4 is a "rubbery" polymer) is very large [13]. Therefore the membrane area requirement is low and thus CRC and VOM only comprise a small fraction in the total processing cost.

\section{B. Effects of Operating and Economic Parameters on Processing Cost}

The basis to use both the $\mathrm{H}_{2} \mathrm{~S}$-selective membrane and the $\mathrm{CO}_{2}$-selective membrane in the process configuration is that the $\mathrm{H}_{2} \mathrm{~S}$-selective membrane exhibits higher $\mathrm{H}_{2} \mathrm{~S} / \mathrm{CH}_{4}$ selectivity and the $\mathrm{CO}_{2}$-selective membrane higher $\mathrm{CO}_{2} / \mathrm{CH}_{4}$ selectivity. However, the permeabilities of the $\mathrm{CO}_{2}$-selective membrane to $\mathrm{CO}_{2}, \mathrm{H}_{2} \mathrm{~S}$ and $\mathrm{CH}_{4}$ are lower than those of the $\mathrm{H}_{2} \mathrm{~S}$-selective membrane. For any membrane configuration, using $\mathrm{CO}_{2}$-selective membranes to separate the same crude natural gas into pipeline-quality natural gas requires a larger membrane area than using $\mathrm{H}_{2} \mathrm{~S}$-selective membranes. Consequently the $\mathrm{CRC}$ and VOM of the membrane configuration using the $\mathrm{CO}_{2}$-selective membrane are higher than those using the $\mathrm{H}_{2} \mathrm{~S}$-selective membrane. The advantage of using $\mathrm{CO}_{2}$-selective membrane to upgrade the crude natural gas is that it can recover $\mathrm{CH}_{4}$ effectively if the feed stream mainly contains $\mathrm{CH}_{4}$ and $\mathrm{CO}_{2}$. However: when the processing cost is dominated by the $\mathrm{CRC}$ and VOM, there is no need to use the $\mathrm{CO}_{2}$ selective membrane in the membrane process configurations. Specifically, if the feed stream only contains $\mathrm{CO}_{2}$ and $\mathrm{CH}_{4}$ and the processing cost of a single stage with $\mathrm{CO}_{2}$ selective membranes is higher than that of a single stage with $\mathrm{H}_{2} \mathrm{~S}$-selective membranes, there is no basis to use the $\mathrm{CO}_{2}$-selective membrane in the membrane process configurations.

The processing cost depends on many factors. Among these factors, the feed flow rate, membrane module cost, wellhead cost and feed pressure are the most important. The effects of these factors on the processing cost for the optimum membrane configuration will be illustrated in the following section.

1) Effect of Feed Flow Rate

For the membrane process configurations without recycle (Figures 1-5), the effect of feed flow rate on the processing cost of is straightforward. The membrane area requirement and labor cost are proportional to the feed flow rate, and the costs of utilities and the compressor module are not present in the membrane process configurations without recycle. Therefore the total plant investment and annual variable operating and maintenance cost are proportional to the feed flow rate. The annual cost of $\mathrm{CH}_{4}$ lost is also proportional to the feed flow rate but the fraction of $\mathrm{CH}_{4}$ lost in the permeate is independent of feed flow rate. Since CRC, VOM and CH4LS are all defined as cost per MSCF of product, these costs are all independent of the feed flow rate. Consequently the processing cost ( $\$$ MSCF of product) is independent of feed flow rate.

2) Effect of Wellhead Price of Natural Gas

The wellhead price of natural gas mainly depends on the market and is very hard to predict. For example the wellhead price peaked at $\$ 2.66 / \mathrm{MSCF}$ (1 MSCF of natural gas $\cong 1000 \mathrm{Btu}$ ) in 1984 and dropped to $\$ 1.59 / \mathrm{MSCF}$ in 1995 . However, in the first half of 1996 , the wellhead cost increased to $\$ 2.16 / \mathrm{MSCF}$. Due to the unpredictability of the wellhead price, the wellhead cost in this study is considered to be in the range of $\$ 1$ to $\$ 5$ per MMBTU (million btu).

Figure 17 shows the effect of wellhead price on processing cost for the optimum 
membrane configuration as a function of $\mathrm{CO}_{2}$ concentration in the feed at 1 mole- $\% \mathrm{H}_{2} \mathrm{~S}$. The effect of wellhead price on processing cost for the optimum membrane configuration as a function of $\mathrm{H}_{2} \mathrm{~S}$ concentration in the feed at 20 mole- $\% \mathrm{CO}_{2}$ is exhibited in Figure 18. At any given $\mathrm{H}_{2} \mathrm{~S}$ and $\mathrm{CO}_{2}$ concentrations in the feed, the processing cost increases proportionally with increasing wellhead price. However, at different $\mathrm{H}_{2} \mathrm{~S}$ and $\mathrm{CO}_{2}$ concentrations in the feed, the gradient of this increase is different.

In the range of $\$ 1$ to $\$ 5 / \mathrm{MMBTU}$ wellhead price, the CRC and VOM are independent of wellhead price. This is because the optimum membrane area requirement is independent of the wellhead price. Furthermore for the membrane process configurations utilizing both $\mathrm{H}_{2} \mathrm{~S}$ - and $\mathrm{CO}_{2}$-selective membranes (Figures 3-5), the optimum membrane area ratio of the $\mathrm{H}_{2} \mathrm{~S}$-selective membrane to the $\mathrm{CO}_{2}$-selective membrane is also independent of the wellhead price. Although CH4LS increases with the wellhead price, the fraction of $\mathrm{CH}_{4}$ recovered in the product stream is independent of the wellhead price.

3) Effect of Membrane Module Cost

The membrane module cost is studied in the range of $\$ 5$ to $\$ 70$ per square feet and the membrane replacement cost is assumed to be one half of the membrane module cost. Figure 19 exhibits the effect of the membrane module cost on the processing cost for the optimum membrane configuration as a function of the $\mathrm{CO}_{2}$ concentration in the feed at 1 mole- $\% \mathrm{H}_{2} \mathrm{~S}$. The effect of the membrane module cost on processing cost for the optimum membrane configuration as a function of the $\mathrm{H}_{2} \mathrm{~S}$ concentration in the feed at 20 mole- $\% \mathrm{CO}_{2}$ is shown in Figure 20.

If the membrane module cost is $\geq \$ 60$ per square feet, it was found that even for the natural gas feed containing 0 mole- $\% \mathrm{H}_{2} \mathrm{~S}$ and 20 mole- $\% \mathrm{CO}_{2}$, the processing cost of the single stage with the $\mathrm{CO}_{2}$-selective membrane is higher than that of single stage with the $\mathrm{H}_{2} \mathrm{~S}$-selective membrane. There is no economic reason to use the $\mathrm{CO}_{2}$-selective membrane in any of the process configurations because of its higher membrane area requirement. All five configurations without recycle (Figures 1-5) are reduced to a single stage with the $\mathrm{H}_{2} \mathrm{~S}$-selective membrane at this membrane module cost.

If the membrane module cost is $\leq \$ 50$ per square feet, to upgrade crude natural gas containing 0 mole- $\% \mathrm{H}_{2} \mathrm{~S}$ and 20 mole- $\% \mathrm{CO}_{2}$ to the pipeline specifications, the processing cost of a single stage with the $\mathrm{CO}_{2}$-selective membrane is lower than that of single stage with the $\mathrm{H}_{2} \mathrm{~S}$-selective membrane, and therefore the $\mathrm{CO}_{2}$-selective membrane should be considered in the membrane process configurations. In this membrane module cost range, although the CRC and VOM depend on the membrane module cost, the optimum total membrane area requirement and optimum membrane area ratio of the $\mathrm{H}_{2} \mathrm{~S}$ selective membrane to the $\mathrm{CO}_{2}$-selective membrane of the two-membrane configuration (Figures 3 to 5) are independent of the membrane module cost. Moreover, CH4LS and the fraction of $\mathrm{CH}_{4}$ recovered in the product stream are also independent of the membrane module cost.

4) Effect of Feed Pressure

The feed pressure in this study is considered in the range of 200 to 1600 psia, which includes the pressure of the most natural basins discovered so far. Feed pressure has a significant effect on membrane area requirement and the fraction of $\mathrm{CH}_{4}$ recovered in the product. Consequently CRC, . V.OM, CH4LS and processing cost change greatly 
with the feed pressure.

(a) Figures 21 and 22 exhibit the processing cost as a function of $\mathrm{CO}_{2}$ concentration in the feed at 1 mole- $\% \mathrm{H}_{2} \mathrm{~S}$. At 200 psia feed pressure, the optimum configuration is the single stage with the $\mathrm{H}_{2} \mathrm{~S}$-selective membrane because of the enormous membrane area requirement when the $\mathrm{CO}_{2}$-selective membrane is used in the membrane configurations.

For feed pressures $\geq 400 \mathrm{psia}$, similar to the base-case, there is a minimum processing cost at a given pressure for the single stage with $\mathrm{H}_{2} \mathrm{~S}$-selective membranes. The minimum point moves to a lower $\mathrm{CO}_{2}$ concentration as the feed pressure increases. At all $\mathrm{CO}_{2}$ concentrations in the feed lower than the $\mathrm{CO}_{2}$ concentration at the minima, the optimum configuration is the single stage with the $\mathrm{H}_{2} \mathrm{~S}$-selective membrane. At all $\mathrm{CO}_{2}$ concentrations in the feed higher than the $\mathrm{CO}_{2}$ concentration at the minima, the membrane configuration utilizing both $\mathrm{H}_{2} \mathrm{~S}$ - and $\mathrm{CO}_{2}$-selective membranes is better than one membrane configuration (single stage with only $\mathrm{H}_{2} \mathrm{~S}$-selective membranes or single stage with only $\mathrm{CO}_{2}$-selective membranes).

(b) Figures 23 to 24 show the processing cost as a function of $\mathrm{H}_{2} \mathrm{~S}$ concentration in the feed at 20 mole- $\% \mathrm{CO}_{2}$. For the single stage with the $\mathrm{CO}_{2}$-selective membrane, similar to the base-case, there are an intersection point at a given pressure. With increasing feed pressure, the intersection points move to lower $\mathrm{H}_{2} \mathrm{~S}$ concentrations.

For feed pressures $\geq 400$ psia, the optimum membrane process configuration at different $\mathrm{H}_{2} \mathrm{~S}$ concentrations in the feed can be summarized as following:

i) At all $\mathrm{H}_{2} \mathrm{~S}$ concentrations in the feed lower than the $\mathrm{H}_{2} \mathrm{~S}$ concentration at the break point of the curves for a single stage with $\mathrm{CO}_{2}$-selective membranes, the best membrane process configuration is the single stage with the $\mathrm{CO}_{2}$-selective membranes;

ii) At all $\mathrm{H}_{2} \mathrm{~S}$ concentrations in the feed higher than the $\mathrm{H}_{2} \mathrm{~S}$ concentration at the break point of the curves for a single stage with $\mathrm{H}_{2} \mathrm{~S}$-selective membranes, the best membrane process configuration is the single stage with the $\mathrm{H}_{2} \mathrm{~S}$-selective membranes;

iii) At all $\mathrm{H}_{2} \mathrm{~S}$ concentrations in the feed higher than the $\mathrm{H}_{2} \mathrm{~S}$ concentration at the break point of the curves for a single stage with $\mathrm{CO}_{2}$-selective membrane and lower than the $\mathrm{H}_{2} \mathrm{~S}$ concentration at the break point of the curves for a single stage with $\mathrm{H}_{2} \mathrm{~S}$ selective membrane, the membrane configuration utilizing both $\mathrm{H}_{2} \mathrm{~S}$ - and $\mathrm{CO}_{2}$-selective membranes is better than either one membrane configuration (single stage with the $\mathrm{H}_{2} \mathrm{~S}$ selective membrane or single stage with the $\mathrm{CO}_{2}$-selective membrane).

\section{Membrane Process Configurations with Recycle}

Three configurations of two stages in a cascade with recycle (Figures 6 to 8) were partially studied and compared with the optimum membrane process configuration without recycle (Figures 1 to 5). For the two stages in cascade with recycle, the permeate of the first stage is compressed and fed to the second stage. The retentate of the second stage is recycled to the first stage, and thus a substantial amount of $\mathrm{CH}_{4}$ is recovered.

Figure 25 shows the plots of processing cost as a function of $\mathrm{CO}_{2}$ concentration in the crude natural gas feed $\left(0-40 \mathrm{~mole}-\% \mathrm{CO}_{2}\right)$ at 1 mole- $\% \mathrm{H}_{2} \mathrm{~S}$. Similar plots were also

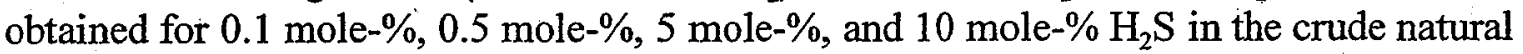
gas. At the base-case operating conditions with the economic parameters listed in Tables $1-3$, the following results were obtained: 
1) For the two stages in cascade with recycle, both stages utilizing the $\mathrm{H}_{2} \mathrm{~S}$ selective membrane, the processing cost increases quickly with increasing $\mathrm{CO}_{2}$ concentration in the feed. At lower $\mathrm{CO}_{2}$ concentration in the feed, the processing cost is lower than that of optimum membrane configuration without recycle. At higher $\mathrm{CO}_{2}$ concentration in the feed, due to the large increase of the compressor module cost and utility cost, the processing cost is higher than that of the optimum membrane. configuration without recycle.

2) For the two stages in cascade with recycle, the first stage utilizing the $\mathrm{H}_{2} \mathrm{~S}$ selective membrane and the second stage utilizing the $\mathrm{CO}_{2}$-selective membrane, the processing cost increases greatly with increasing of $\mathrm{CO}_{2}$ concentration in the feed. In contrast with two stages in cascade with recycle, both stages utilizing the $\mathrm{H}_{2} \mathrm{~S}$-selective membrane, it was found that the processing cost of this configuration is higher at the lower $\mathrm{CO}_{2}$ concentration in the feed and lower at higher $\mathrm{CO}_{2}$ concentration in the feed. However at higher $\mathrm{CO}_{2}$ concentrations in the feed, the processing cost of this configuration is still higher than that of the optimum membrane processing configuration without recycle.

In the base-case, when crude natural gas does not contain the $\mathrm{H}_{2} \mathrm{~S}$, our previous study has shown that a single stage with $\mathrm{CO}_{2}$-selective membranes is the best configuration among the five membrane configurations without recycle (Figures 1-5). However, for the $\mathrm{CO}_{2}$-selective membrane with high $\mathrm{CO}_{2} / \mathrm{CH}_{4}$ selectivity (e.g. polyimides developed in our lab), the question remains whether there are any $\mathrm{CO}_{2}$ concentrations where it is advantageous to use two stages in cascade with recycle. The answer is decided by the two contradicting factors: the cost of $\mathrm{CH}_{4}$ loss, and the costs of the compressor and utilities (electricity for the compressor).

a). For the single stage with $\mathrm{CO}_{2}$-selective membranes, a relatively larger amount of $\mathrm{CH}_{4}$ is lost in the permeate stream but there are no costs for the compressor and utilities;

b). For the two stages in cascade with recycle, both stages utilizing $\mathrm{CO}_{2}$-selective membranes, the second stage recovers most of $\mathrm{CH}_{4}$ in the permeate stream of first stage, but with the added costs for the compressor and utilities.

Figure 26 exhibits the processing costs of single stage with $\mathrm{CO}_{2}$-selective membranes and two stages in cascade with recycle, both stages utilizing $\mathrm{CO}_{2}$-selective membranes. At all $\mathrm{CO}_{2}$ concentrations in the feed higher than 2 mole- $\%$, the processing cost of single stage with $\mathrm{CO}_{2}$-selective membranes is lower than that of two stages in cascade with recycle, both stages utilizing $\mathrm{CO}_{2}$-selective membranes.

Since the pipeline specification for $\mathrm{CO}_{2}$ is not very stringent $\left(2 \mathrm{~mole}-\% \mathrm{CO}_{2}\right)$, and the selectivity of $\mathrm{CO}_{2}$ to $\mathrm{CH}_{4}$ is very high for the polyimide membranes (the selectivity, á, is about 60), only a relatively small fraction of $\mathrm{CH}_{4}$ is lost in the permeate stream when using a single stage with $\mathrm{CO}_{2}$-selective membranes to upgrade the crude natural gas. The cost of the compressor and utilities for the two stages in cascade with recycle is proportional to the permeate flow rate of the first stage and increases greatly with the increase $\mathrm{CO}_{2}$ concentration in the feed. However, even at lower $\mathrm{CO}_{2}$ concentration in the feed, the cost of the compressor and utilities surpasses the cost of $\mathrm{CH}_{4}$ that this configuration could recover. Therefore, for the base-case, a single stage with $\mathrm{CO}_{2}$ selective membranes is better than two stages in cascade with recycle, both stages 
utilizing $\mathrm{CO}_{2}$-selective membranes when the crude natural gas does not contain $\mathrm{H}_{2} \mathrm{~S}$.

\section{Comparison of Membrane Process without Recycle and Adsorption}

Figure 27 shows the processing cost as a function of total acid gas concentration in feed for optimum membrane process configurations and gas absorption. Since diethanolamine is the chemical solvent and has equal selectivity to $\mathrm{H}_{2} \mathrm{~S}$ and $\mathrm{CO}_{2}$, the processing cost only changes with the total amount of acid gas [16]. The selectivities of $\mathrm{CO}_{2}$-selective membranes and $\mathrm{H}_{2} \mathrm{~S}$-selective membranes vary widely and have a significant impact on the processing cost. The plot of Figure 27 can be summarized as follows:

1). For the crude natural gas containing 0 mole- $\% \mathrm{H}_{2} \mathrm{~S}$, the processing cost for the membrane process configuration is lower than that of gas absorption. This is because the pipeline specification for the $\mathrm{CO}_{2}(\leq 2$ mole- $\%)$ is not very stringent and $\mathrm{CO}_{2} / \mathrm{CH}_{4}$ selectivity of $\mathrm{CO}_{2}$-selective membrane is very high. Therefore the membrane requirement is low and only a small portion of $\mathrm{CH}_{4}$ is lost in the permeate stream.

2). For the crude natural gas containing some amount of $\mathrm{H}_{2} \mathrm{~S}(0.1$ to 10 mole- $\%)$, the processing cost plots of the membrane process intersect with that of gas absorption. At higher $\mathrm{H}_{2} \mathrm{~S}$ concentrations in the feed, the intersection points move to higher processing costs. At all acid gas concentrations in the feed lower than that at the intersection point, the processing costs are higher than that of gas absorption. This is because a large amount of $\mathrm{CH}_{4}$ is lost in the permeate stream and the energy requirement of the stripper in the gas absorption process is not high. At all acid gas concentration in the feed higher than that at the intersection point, the cost of regenerating diethanolamine solvent is so significant that the processing cost of the gas absorption is higher than that of the membrane process. 


\section{REFERENCES}

[1] U.S. Dept. of Energy, "Natural Gas", Section 4 in: Monthly Energy Review, DOE/EPA0035, November 1996.

[2] Energy and Environmental Analysis, Inc., 1655 North Fort Drive, Suite 600, Arlington, Virginia 22209, "Chemical composition of discovered and undiscovered natural gas in the United States - 1993 Updated”, Volumes 1-3, Topical Report for the Gas Research Institute, Chicago, IL, December 1993.

[3] W.J. Koros, "Gas separation", Chap. 3 in: Membrane Separation Systems, A Research and Development Needs Assessment, U.S. Dept. of Energy, Office of Energy Research, Office of Program Analysis, Vol. 2, DOE/ER/30133-H1, April 1990, pp. 26-27.

[4] B.D. Bhide and S.A. Stern, Membrane processes for the removal of acid gases from natural gas. I. Optimization of operating conditions and process configurations, J. Membrane Sci., 81 (1993) 209-237.

[5] B.D. Bhide and S.A. Stern, Membrane processes for the removal of acid gases fro natural gas, II. Effect of economic parameters and membrane properties, J. Membrane Sci., 81 (1993) 239252.

[6] S.A. Stern, H.S. Meyer, V.K. Venkataraman, and H.D. Shoemaker, Upgrading of raw natural gas using high-performance polymer membranes, Presented at the 1993 Meeting of the American Filtration Society/North American Membrane Society, Rosemont, IL.

[7] R. Spillman, Economics of gas separation membrane processes, Chap. 13 in : R.D. Noble and S.A. Stern (Eds.), Membrane Separation Technology. Principles and Applications, Elsevier Science, Amsterdam, 1995, pp. 589-667.

[8] S.A. Stern, New developments in membrane processes for gas separations, Chap.1 in: M.B. Chenoweth (Ed), Synthetic Membranes, MMI Press Symposium Series, Vol. 5, Harwood Academic Publishers, New York, 1986, pp. 1-37.

[9] W.J. Koros and R.T. Chern, Separation of gaseous mixtures using polymer membranes, Chap. 20 in: R.W. Rousseau (Ed.), Handbook of Separation Process Technology, Wiley New York, 1987, pp. 863-953.

[10] R.R. Zolandz and G.K. Fleming, Gas permeation, Part II in: W.S.W. Ho and K.K. Sirkar (Eds.), Membrane Handbook, Van Nostrand Reinhold; New York, 1992, pp. 17-101.

[11] A.Y. Houde, B.Krishnakumar, S.G. Charati, and S.A. Stern, Permeability of dense (homogeneous) cellulose acetate membranes to methane, carbon dioxide, and their mixtures at elevated pressures, J. Appl. Polym. Sci., 62 (1996) 2181-2192.

[12] S.A. Stern, H. Kawakami, A.Y. Houde, and G. Zhou, Material and process for separating carbon dioxide from methane, U.S. Patent 5,591,250 of January 7, 1997.

[13] G. Chatterjee, A.A. Houde, and S.A. Stern, Poly(ether urethane) and poly(ether urethane urea) membranes with high $\mathrm{H}_{2} \mathrm{~S} / \mathrm{CH}_{4}$ selectivity, J. Membrane Sci., 135 (1997) 99-106.

[14] G.V. Reklaitis, A. Ravindran, and K.M. Ragsdell, Engineering Optimization: Methods and Applications, Wiley, New York, 1983.

[15]. S.A. Stern, P.A. Rice, and J. Hao, Upgrading Natural Gas Via Membrane Separation Processes, Progress Reports to Morgantown Energy Technology Center, September 1996October 1997.

[16]. S.A. Stern, B. Krishnakumar, G. Chatterjee and A.A. Houde, Upgrading Natural Gas Via Membrane Separation Processes, Progress Report to Morgantown Energy Technology Center, 
APPENDIX I

Mathematical Derivation of Membrane Separation

1. Single Stage with $\mathrm{H}_{2} \mathrm{~S}$-Selective (or $\mathrm{CO}_{2}$-Selective) Membrane

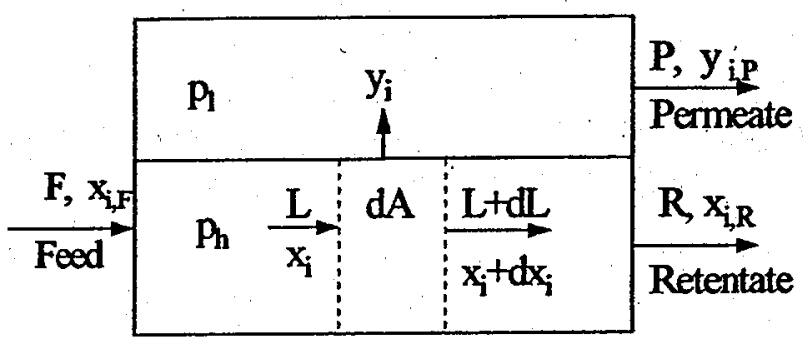

Material balance for component $i$ is:

$$
(L+d L) \cdot\left(x_{i}+d x_{i}\right)+d A \cdot J_{i}=L \cdot x_{i}
$$

Equation (1) can be written into

$$
L \cdot d x_{i}+x_{i} \cdot d L+d L \cdot d x_{i}+d A \cdot \frac{\bar{P}_{i}}{\sigma}\left(p_{h} \cdot x_{i}-p_{i} \cdot y_{i}\right)=0
$$

One can neglect second order differential and simplify equation (2) into

$$
d\left(L \cdot x_{i}\right)+d A \cdot \frac{\bar{P}_{i}}{\sigma}\left(p_{h} \cdot x_{i}-p_{l} \cdot y_{i}\right)=0
$$

For the material balance of $\mathrm{n}$ components, one can obtain

$$
d L+d A \cdot \sum_{i=1}^{n} \frac{\bar{P}_{i}}{\sigma}\left(p_{h} \cdot x_{i}-p_{l} \cdot y_{i}\right)=0
$$

Since

$$
d\left(L \cdot x_{i}\right)=x_{i} \cdot d L+L \cdot d x_{i}
$$

one can obtain

$$
\frac{d x_{i}}{d A}=\frac{1}{L}\left[\frac{d\left(L x_{i}\right)}{d A}-x_{i} \frac{d L}{d A}\right]
$$


Substituting equations (3) and (4) into equation (5), one can obtain

$$
\frac{d x_{i}}{d A}=-\frac{1}{L}\left[\frac{\bar{P}_{i}}{\sigma}\left(p_{h} \cdot x_{i}-p_{i} \cdot y_{i}\right)-x_{i} \sum_{j=1}^{n} \frac{\bar{P}_{j}}{\sigma}\left(p_{h} \cdot x_{j}-p_{l} \cdot y_{j}\right)\right]
$$

From equation (6) and equation (4), one obtains

$$
\frac{d x_{i}}{d L}=\frac{\left[\frac{\bar{P}_{i}}{\sigma}\left(p_{h} \cdot x_{i}-p_{i} \cdot y_{i}\right)-x_{i} \sum_{j=1}^{n} \frac{\bar{P}_{j}}{\sigma}\left(p_{h} \cdot x_{j}-p_{i} \cdot y_{j}\right)\right]}{L \cdot \sum_{j=1}^{n} \frac{\bar{P}_{j}}{\sigma}\left(p_{h} \cdot x_{j}-p_{l} \cdot y_{j}\right)}
$$

Since the flow pattern is assumed to be cross-flow, the permeate side mole fractions at any point are given by the ratio of the local component flux to the total local flux,

$$
y_{i}=\frac{J_{i}}{\sum_{j=1}^{n} J_{j}}=\frac{\frac{\bar{P}_{i}}{\delta}\left(p_{h} \cdot x_{i}-p_{i} \cdot y_{i}\right)}{\sum_{j=1}^{n} \frac{\bar{P}_{j}}{\delta}\left(p_{h} \cdot x_{j}-p_{i} \cdot y_{j}\right)}
$$

Therefore, equation (7) can be rewritten into:

$$
\frac{d x_{i}}{d L}=\frac{y_{i}-x_{i}}{L}
$$

The definition of stage cut $\theta$ is

$$
\theta=\frac{F-L}{F}
$$

So

$$
d L=-F \cdot d \theta
$$

Substituting equation (10) to equation (9), one obtains

$$
\frac{d x_{i}}{d \theta}=-\frac{y_{i}-x_{i}}{(1-\theta)}
$$

where $\quad x_{i}=x_{i, F} \quad$ at $\theta=0$

Similarly, one can substitute equation (10) to equation (4) and obtain

$$
\frac{d A}{d \theta}=\frac{F}{\sum_{i=1}^{n} \frac{\widetilde{P}_{j}}{\sigma}\left(p_{h} \cdot x_{i}-p_{l} \cdot y_{i}\right)}
$$

where $\quad \mathrm{A}=0$

at $\theta=0$ 
The overall or outlet permeate composition, $y_{i, P}$, can be obtained from the material balance over the entire module:

$$
F \cdot x_{i, F}=P \cdot y_{i, P}+R \cdot x_{i, R}
$$

From the definition of stage cut, the above equation can be rewritten into:

$$
y_{i, P}=\frac{x_{i, F}-(1-\theta) \cdot x_{i, R}}{\theta}
$$

where $x_{i, R}$ is the mole fraction of component $\mathrm{i}$ in the overall or outlet retentate stream.

It should be noted that numerical (Runge-Kutta) method was used to solve equations (11) and (12). In equations (11) and (12), $\mathrm{y}_{\mathrm{i}}$ is calculated by trial and error method. For the feed containing $\mathrm{CH}_{4}, \mathrm{CO}_{2}$ and $\mathrm{H}_{2} \mathrm{~S}$, the detail steps of calculating $\mathrm{y}_{\mathrm{i}}$ are as follows, where subscript 0 represents $\mathrm{CH}_{4}, 1$ represents $\mathrm{CO}_{2}$ and 2 represents $\mathrm{H}_{2} \mathrm{~S}$.

1). Assuming $\mathrm{y}_{\mathrm{CH} 4}\left(\mathrm{y}_{1}\right)$ a given value;

2). For the cross-flow, one can have $y_{i}=\frac{J_{i}}{\sum_{j=1}^{2} J_{j}}$

$$
\text { Therefore } \begin{aligned}
\frac{y_{1}}{y_{i}} & =\frac{J_{1}}{J_{i}}=\frac{J_{1}}{\left(\bar{P}_{i} / \sigma\right) \cdot\left(p_{h} \cdot x_{i}-p_{i} \cdot y_{i}\right)} \\
y_{i} & =\frac{\left.\overline{(P}_{i} / \sigma\right) \cdot p_{h} \cdot y_{1} \cdot x_{i}}{\left.J_{1}+\overline{(P}_{i} / \sigma\right) \cdot p_{l} \cdot y_{1}} \quad \text { where } \mathrm{i}=2 \text { and } 3
\end{aligned}
$$

From above equation, one can calculate $\mathrm{y}_{2}$ and $\mathrm{y}_{3}$. Since $\sum_{j=1}^{3} y_{j}=1$, one can check and recalculate $\mathrm{y}_{1}$, and repeat above steps until satisfied accuracy is achieved. 


\section{Single Stage with both $\mathrm{H}_{2} \mathrm{~S}$ - and $\mathrm{CO}_{2}$-Selective Membranes}

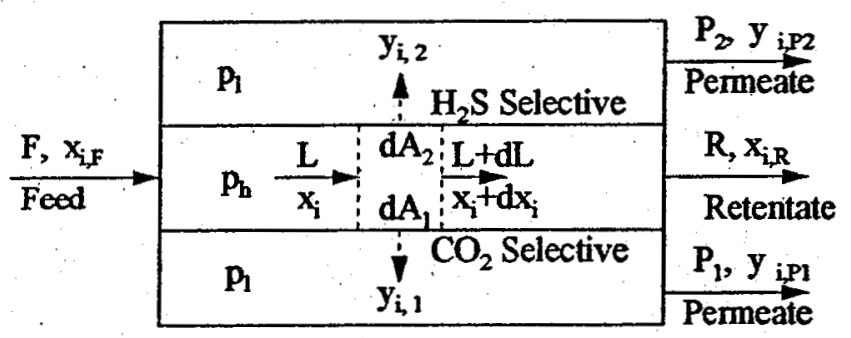

Membrane area ratio:

$\mathrm{dA}_{2} / \mathrm{dA}_{1}=\mathrm{H}_{2} \mathrm{~S}$-Selective Membrane Area $/ \mathrm{CO}_{2}$-Selective membrane Area

Material balance for component $i$ is:

$$
(L+d L) \cdot\left(x_{i}+d x_{i}\right)+d A_{1} \cdot J_{i, 1}+d A_{2} \cdot J_{i, 2}=L \cdot x_{i}
$$

Let $\alpha=d A_{2} / d A_{1}$ and $\beta=d A_{2} /\left(d A_{1}+d A_{2}\right)$, then $\beta=\frac{\alpha}{1+\alpha}$ and equation (1) can be written into

$$
L \cdot d x_{i}+x_{i} \cdot d L+d L \cdot d x_{i}+d A_{1} \cdot\left(J_{i, 1}+\alpha \cdot J_{i, 2}\right)=0
$$

One can neglect second order differential and simplify equation (2) into

$$
d\left(L \cdot x_{i}\right)+\frac{d A}{1+\alpha}\left(J_{i, 1}+\alpha \cdot J_{i, 2}\right)=0
$$

where $\quad d A=d A_{1}+d A_{2}=(1+\alpha) d A_{1}$

For the material balance of $\mathbf{n}$ components, one can obtain

$$
d L+\frac{d A}{1+\alpha} \sum_{i=1}^{n}\left(J_{i, 1}+\alpha \cdot J_{i, 2}\right)=0
$$

Since

$$
d\left(L \cdot x_{i}\right)=x_{i} \cdot d L+L \cdot d x_{i}
$$

one can obtain 


$$
\frac{d x_{i}}{d A}=\frac{1}{L}\left[\frac{d\left(L x_{i}\right)}{d A}-x_{i} \frac{d L}{d A}\right]
$$

Substituting equations (3) and (4) into equation (5), one can obtain

$$
\frac{d x_{i}}{d A}=-\frac{1}{L} \frac{1}{1+\alpha}\left[\left(J_{i, 1}+\alpha \cdot J_{i, 2}\right)-x_{i} \sum_{j=1}^{n}\left(J_{j, 1}+\alpha \cdot J_{j, 2}\right)\right]
$$

From equation (6) and equation (4), one obtains

$$
\frac{d x_{i}}{d L}=\frac{\left[\left(J_{i, 1}+\alpha \cdot J_{i, 2}\right)-x_{i} \sum_{j=1}^{n}\left(J_{j, 1}+\alpha \cdot J_{j, 2}\right)\right]}{L \cdot \sum_{j=1}^{n}\left(J_{j, 1}+\alpha \cdot J_{j, 2}\right)}
$$

The definition of stage cut $\theta$ is

$$
\theta=\frac{F-L}{F}
$$

So

$$
d L=-F \cdot d \theta
$$

Substituting equation ( 8 ) to equation (7), one obtains

$$
\begin{aligned}
\frac{d x_{i}}{d \theta}= & -\frac{\left[\left(J_{i, 1}+\alpha \cdot J_{i, 2}\right)-x_{i} \sum_{j=1}^{n}\left(J_{j, 1}+\alpha \cdot J_{j, 2}\right)\right]}{(1-\theta) \cdot \sum_{j=1}^{n}\left(J_{j, 1}+\alpha \cdot J_{j, 2}\right)} \\
& =\frac{\left[\left(J_{i, 1}+\beta /(1-\beta)^{\left.\left.\cdot J_{i, 2}\right)-x_{i} \sum_{j=1}^{n}\left(J_{j, 1}+\beta /(1-\beta)^{\cdot} J_{j, 2}\right)\right]}\right.\right.}{(1-\theta) \cdot \sum_{j=1}^{n}\left(J_{j, 1}+\beta /(1-\beta)^{\cdot} J_{j, 2}\right)}
\end{aligned}
$$

where $\quad x_{i}=x_{i, F} \quad$ at $\theta=0$

One can substitute equation (8) to equation (4) and obtain

$$
\begin{aligned}
\frac{d A}{d \theta} & =\frac{F \cdot(1+\alpha)}{\sum_{j=1}^{n}\left(J_{j, 1}+\alpha \cdot J_{j, 2}\right)} \\
& =\frac{F}{\sum_{j=1}^{n}\left(J_{j, 1} \cdot(1-\beta)+\beta \cdot J_{j, 2}\right)}
\end{aligned}
$$


where $\quad \mathrm{A}=0 \quad$ at $\theta=0$

It should be noted that the increment of stage cut of $\mathrm{CO}_{2}$-selective membrane

$$
d \theta_{1}=\frac{\sum_{j=1}^{n} J_{j, 1} d A_{1}}{\sum_{j=1}^{n}\left(J_{j, 1} d A_{1}+J_{j, 2} d A_{2}\right)} d \theta=\frac{\sum_{j=1}^{n} J_{j, 1}}{\sum_{j=1}^{n}\left(J_{j, 1}+\alpha \cdot J_{j, 2}\right)} d \theta
$$

The increment of flow rate of component $i$ in the permeate side of $\mathrm{CO}_{2}$-selective membrane

$$
d P_{i, 1}=F \cdot y_{i, 1} \cdot d \theta_{1}
$$

The increment of stage cut of $\mathrm{H}_{2} \mathrm{~S}$-selective membrane

$$
d \theta_{2}=\frac{\sum_{j=1}^{n} \alpha \cdot J_{j, 2}}{\sum_{j=1}^{n}\left(J_{j, 1}+\alpha \cdot J_{j, 2}\right)} d \theta
$$

The increment of flow rate of component $i$ in the permeate side of $\mathrm{H}_{2} \mathrm{~S}$-selective membrane

$$
d P_{i, 2}=F \cdot y_{i, 2} \cdot d \theta_{2}
$$

For the cross-flow pattern, the permeate side mole fractions at any point are given by the ratio of the local component flux to the total local flux,

$$
\begin{gathered}
y_{i, 1}=\frac{J_{i, 1}}{\sum_{j=1}^{n} J_{j, 1}}=\frac{\bar{P}_{i}\left(p_{h} \cdot x_{i}-p_{l} \cdot y_{i, 1}\right)}{\sum_{j=1}^{n} \bar{P}_{j}\left(p_{h} \cdot x_{j}-p_{l} \cdot y_{j, 1}\right)} \\
y_{i, 2}=\frac{J_{i, 2}}{\sum_{j=1}^{n} J_{j, 2}}=\frac{\bar{P}_{i}\left(p_{h} \cdot x_{i}-p_{l} \cdot y_{i, 2}\right)}{\sum_{j=1}^{n} \bar{P}_{j}\left(p_{h} \cdot x_{j}-p_{l} \cdot y_{j, 2}\right)}
\end{gathered}
$$

The overall or outlet permeate composition, $y_{i, P}$, can be obtained from the material balance over the entire module:

$$
y_{i, P}=\frac{x_{i, F}-(1-\theta) \cdot x_{i, R}}{\theta}
$$

where $x_{i, R}$ is the mole fraction of component $i$ in the overall or outlet retentate stream. 


\section{APPENDIX II}

\section{Optimization Methodology}

It was mentioned in Section III.B that the one-variable optimization method used in this study to find the optimum decision variables was the Golden Section method [15], which is one of the most effective "region-elimination" methods for the unimodal problems. As an example of this method, the steps that must be used to optimize the decision variables $\theta$ and $\beta$ for process configuration 3, i.e., the single stage with both $\mathrm{H}_{2} \mathrm{~S}$ and $\mathrm{CO}_{2}$-selective membranes, are listed below:

1) Find the bracket of $\beta$ that contains the optimum $\beta$, i.e., the lower bound $\beta_{L}$ and the upper bound $\beta_{U} ; \quad$ (note: $\beta_{L} \geq 0$ and $\beta_{U} \leq 1$ ).

2) Use the Golden Section method to find the new points $\beta_{L U}=\beta_{L}+0.318^{*}\left(\beta_{U}\right.$ $\left.\beta_{L}\right)$, and $\beta_{U L}=\beta_{U}-0.318^{*}\left(\beta_{U}-\beta_{L}\right)$;

3) Find the optimum values of $\theta$ at $\beta_{L}, \beta_{L U}, \beta_{U L}$, and $\beta_{U}$, respectively; calculate the processing cost at these four points;

4) Reduce the bracket of $\beta$. If the processing cost at $\beta_{L}$ is larger than that at $\beta_{U}$, then set $\beta_{L}=\beta_{L U}, \beta_{L U}=\beta_{U L}$ and calculate the new $\beta_{U L}$ from step 2; otherwise set $\beta_{U}=\beta_{U L}$, $\beta_{U L}=\beta_{L U}$ and calculate the new $\beta_{L U}$ from step 2;

5) Find the optimum values of $\theta$ at new $\beta_{U L}$ (or $\beta_{L U}$ ) and calculate the processing cost at this point;

6) Check the bracket length $\left(\beta_{U}-\beta_{L}\right)$ to see if the desired termination criterion is met or not. If the criterion is met, terminate; if not, go to step 4.

It should be noted that the optimum $\theta$ is the minimum stage-cut that can produce pipeline-quality natural gas (either one or both constraints are active). Based on this criterion, implementation of the above step 3 is straightforward. Furthermore, extensive calculation results have proven that processing cost is unimodal to $\beta$ at optimum $\theta$. 


\section{TABLES}

\section{Table 1}

\section{Operating and Feed Conditions Used in Process Simulations} Feed composition: 0.1-10 mole- $\% \mathrm{H}_{2} \mathrm{~S}, 0-40$ mole- $\%$ of $\mathrm{CO}_{2}$, balance $\mathrm{CH}_{4}$ Product purity target: $\leq 2$ mole- $\% \mathrm{CO}_{2}$ and $\leq 4$ ppm $\mathrm{H}_{2} \mathrm{~S}$

Feed flow rate: 35 MMSCFD (million standard $\mathrm{ft}^{3} /$ day)

Feed pressure: 800 psia (54 atm); Permeate pressure: 20 psia (1.4 atm)

Flow pattern inside permeator module: Cross-flow

Effective membrane thickness: $1000 \stackrel{\circ}{A}$

Table 2

Permeability and Selectivity Values Used in Process Simulations

\begin{tabular}{|c|c|c|c|}
\hline $\begin{array}{c}\text { Polymer } \\
\text { Membranes }\end{array}$ & $\bar{P}\left(\mathrm{CH}_{4}\right)^{*}$ & $\begin{array}{c}\mathrm{CO}_{2} / \mathrm{CH}_{4} \\
\text { Selectivity }\end{array}$ & $\begin{array}{c}\mathrm{H}_{2} \mathrm{~S} / \mathrm{CH}_{4} \\
\text { Selectivity }\end{array}$ \\
\hline $\begin{array}{c}\mathrm{H}_{2} \text { S Selective } \\
\text { (PU4) }\end{array}$ & $2 \times 10^{-10}$ & 16 & 75 \\
\hline $\begin{array}{c}\mathrm{CO}_{2} \text { Selective } \\
\text { (Polyimide) }\end{array}$ & $0.1 \times 10^{-10}$ & 60 & 15 \\
\hline
\end{tabular}

* Units of permeability coefficients $\bar{P}:\left[\mathrm{cm}^{3} \cdot(\mathrm{STP}) \cdot \mathrm{cm}\right] /\left(\mathrm{s} \cdot \mathrm{cm}^{2} \cdot \mathrm{cmHg}\right)$

Given temperature: $95^{\circ} \mathrm{F}\left(35^{\circ} \mathrm{C}\right)$ 
Table 3

Economic Parameters and Assumptions

\section{Total Plant Investment(TPI):}

Membrane module cost(MC): $\$ 10 / \mathrm{ft}^{2}$ (include cost of membrane element)

Compressor module cost(CC): $\$ 8650 \times(H P / \eta)^{0.82}$

Fixed $\operatorname{cost}(\mathrm{FC})=\mathrm{MC}+\mathrm{CC}$

Base plant cost $(\mathrm{BPC})=1.12 \times \mathrm{FC}$ (includes home office cost $=0.12 \times \mathrm{FC}$ )

Project contingency $(\mathrm{PC})=0.20 \times \mathrm{BPC}$

Total facilities investment(TFI $)=B P C+P C$

Start-up cost (SC) $=0.10 \times \mathrm{VOM}$ (see below for the explanation of VOM)

Total Plant Investment(TPI) $=\mathrm{TFI}+\mathrm{SC}$

Annual Variable Operating \& Maintenance Cost(VOM):

Contract \& material maintenance $\operatorname{cost}(\mathrm{CMC})=0.05 \times \mathrm{TFI}$

Local taxes \& insurance $(\mathrm{LTI})=0.015 \times \mathrm{TFI}$

Direct labor cost(DL): $8 \mathrm{hr}$./day per 25 MMSCFD of feed (hourly wage: \$15)

Labor overhead $\operatorname{cost}(\mathrm{LOC})=1.15 \times \mathrm{DL}$

Membrane replacement cost(MRC): $\$ 5 / \mathrm{ft}^{2}$

Utility cost(UC): $\$ 0.07 / \mathrm{KWHr}$

Variable Operating \& Maintenance Cost(VOM):

$$
\mathrm{VOM}=\mathrm{CMC}+\mathrm{LTI}+\mathrm{DL}+\mathrm{LOC}+\mathrm{MRC}+\mathrm{UC}
$$

Gas Processing Cost(GPC): -

Annual capital related cost $(\mathrm{CRC})=0.2 \times \mathrm{TPI}$ ( 5 -year payout period)

Feed gas cost(or Cost of $\mathrm{CH}_{4}$ losses) (CH4LS):\$2.0/MMBTU

Annual variable operating \& maintenance cost(VOM) (see above)

Gas process cost $(\mathrm{GPC})=\mathrm{CRC}+\mathrm{CH} 4 \mathrm{LS}+\mathrm{VOM}$ (MSCF of product)

Other Assumptions:

Membrane life: 4 year

On-Stream factor: $96 \%$

Compressor efficiency $(\eta): 80 \%$. 


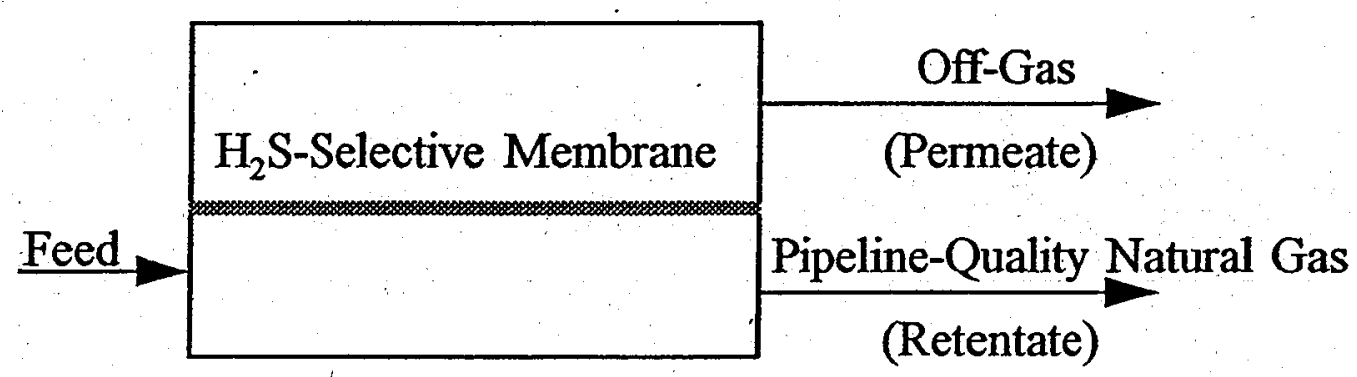

Figure 1: Single Permeation Stage with $\mathrm{H}_{2} \mathrm{~S}$-Selective Membranes

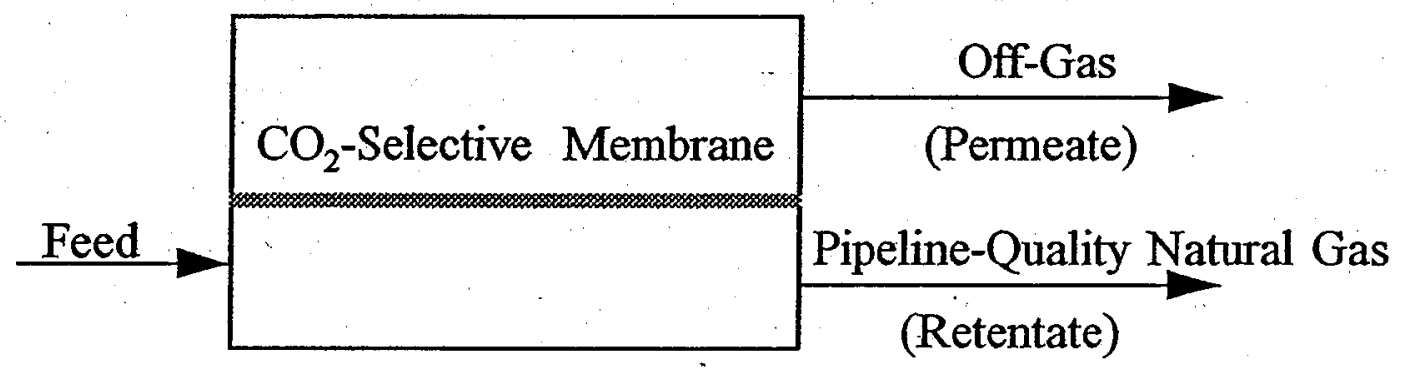

Figure 2: Single Permeation Stage with $\mathrm{CO}_{2}$-Selective Membranes

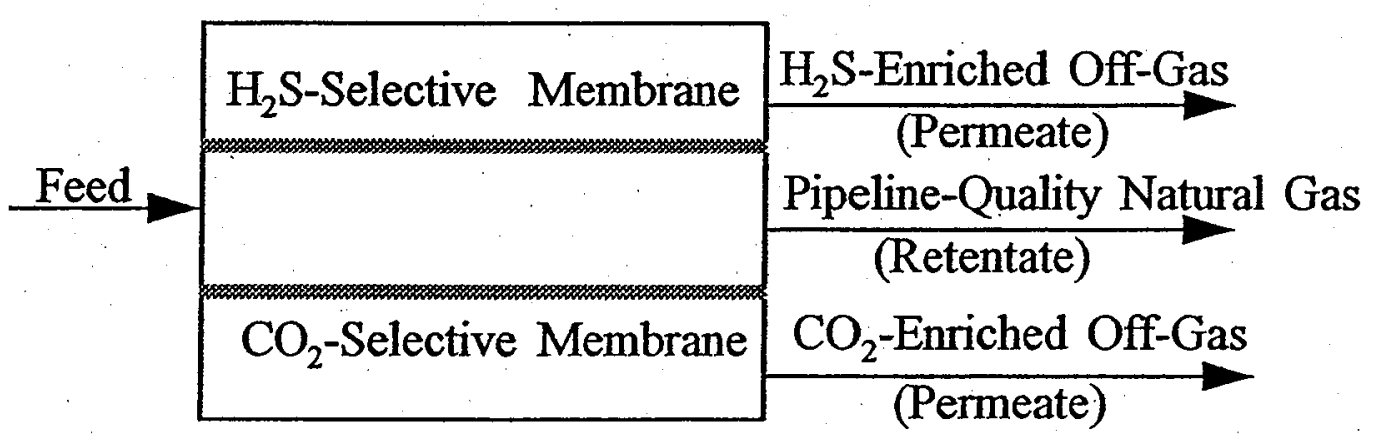

Figure 3: Single Permeation Stage with both $\mathrm{H}_{2} \mathrm{~S}$ - and $\mathrm{CO}_{2}$-Selective Membranes 


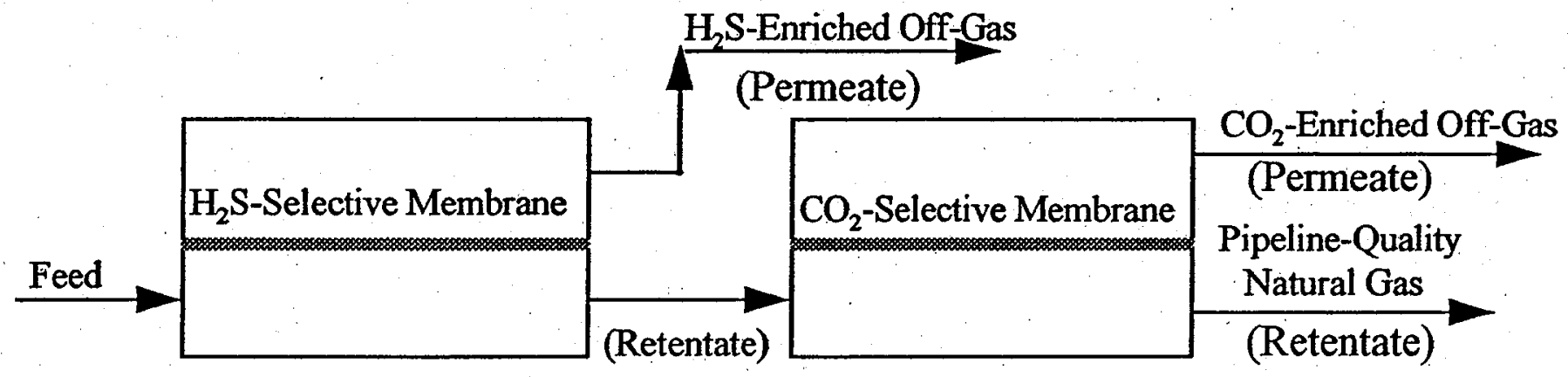

Figure 4: Two Permeation Stages in Series with $\mathrm{H}_{2} \mathrm{~S}$-Selective Membranes in the First Stage and $\mathrm{CO}_{2}$-Selective Membranes in the Second Stage

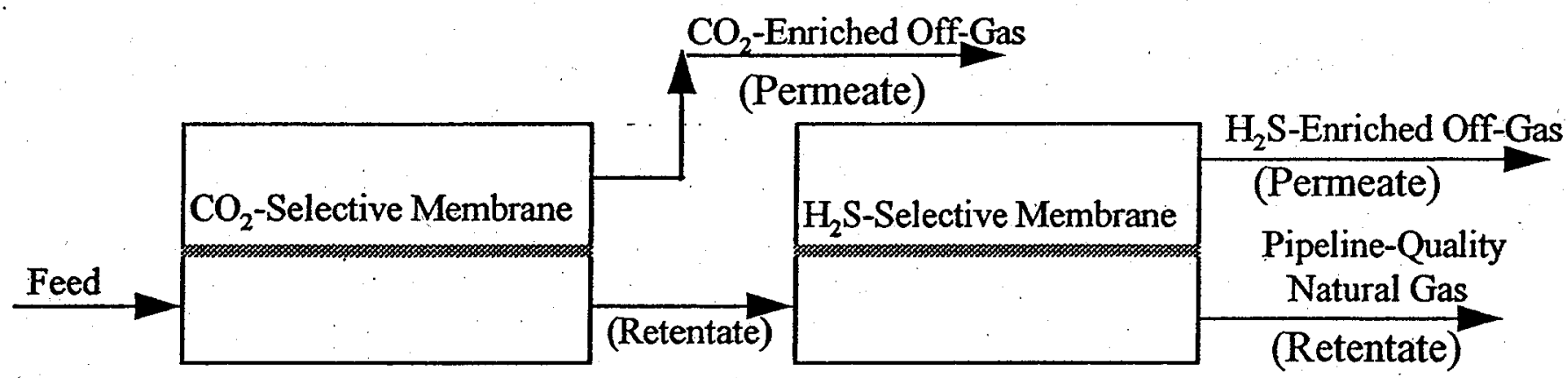

Figure 5: Two Permeation Stages in Series with $\mathrm{CO}_{2}$-Selective Membranes in the First Stage and $\mathrm{H}_{2} \mathrm{~S}$-Selective Membranes in the Second Stage 


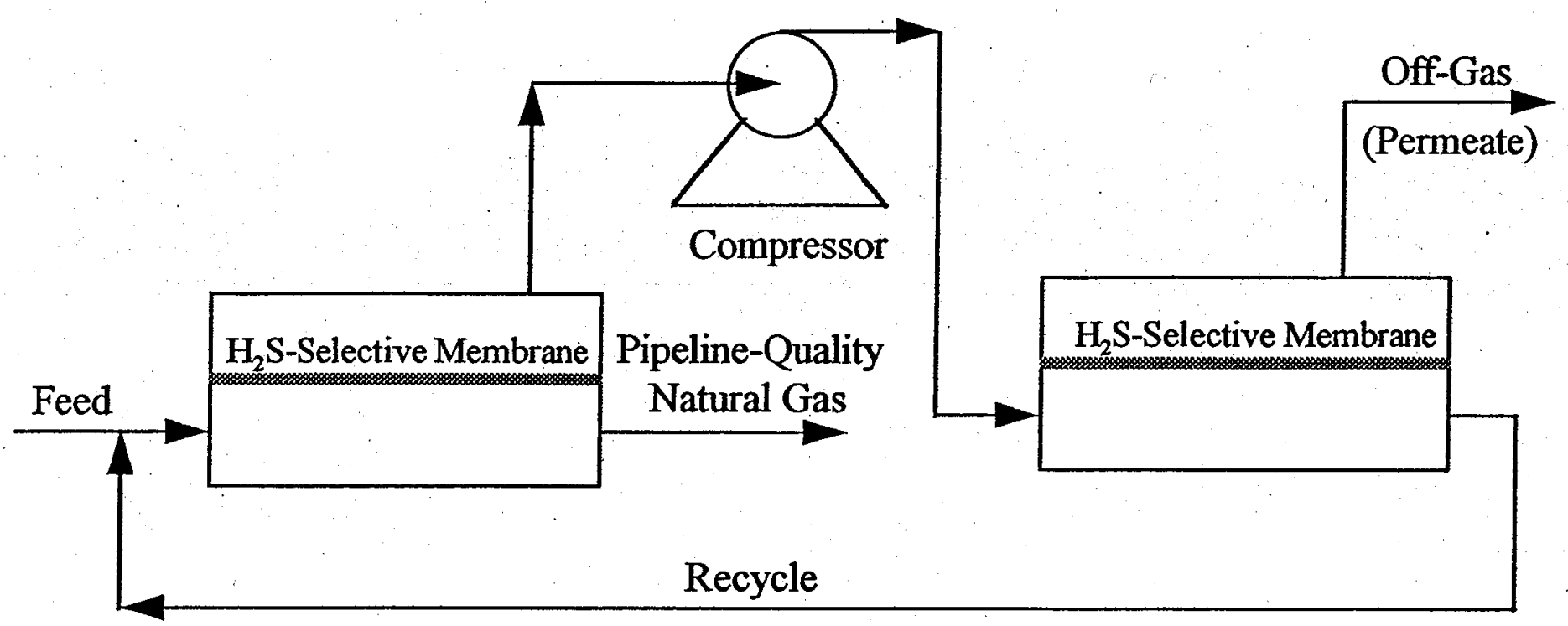

Figure 6: Two Permeation Stages in Cascade with Recycle, Both Stages Utilizing $\mathrm{H}_{2} \mathrm{~S}$-Selective Membranes

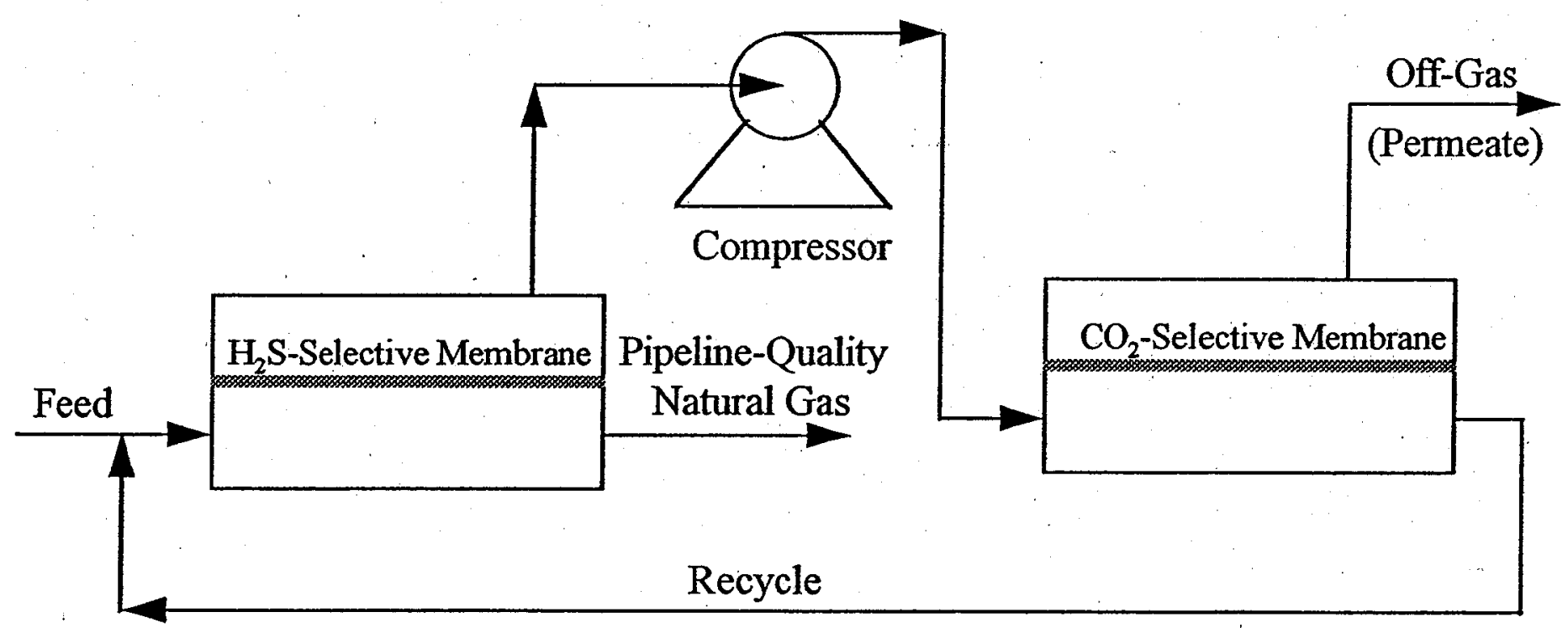

Figure 7: Two Permeation Stages in Cascade with Recycle, First Stages Utilizing $\mathrm{H}_{2} \mathrm{~S}$-Selective Membranes and Second Stage Utilizing $\mathrm{CO}_{2}$-Selective Membranes 


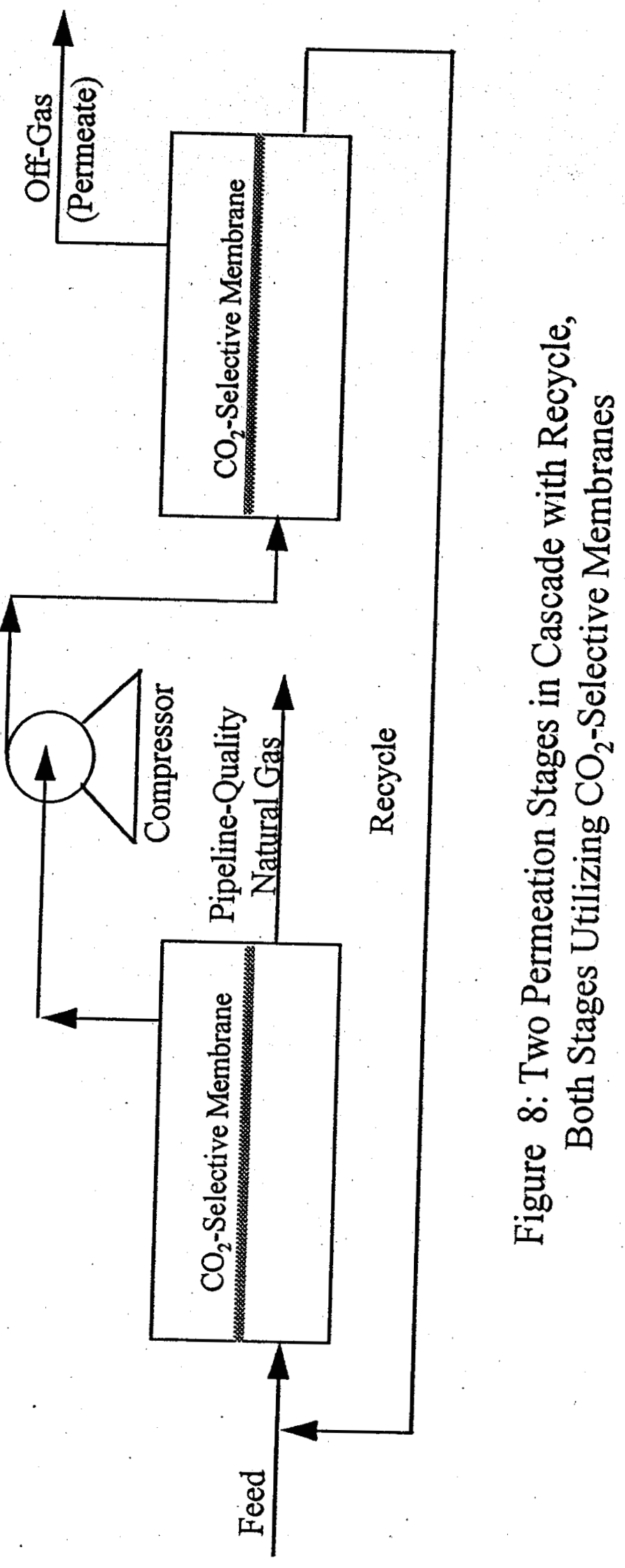




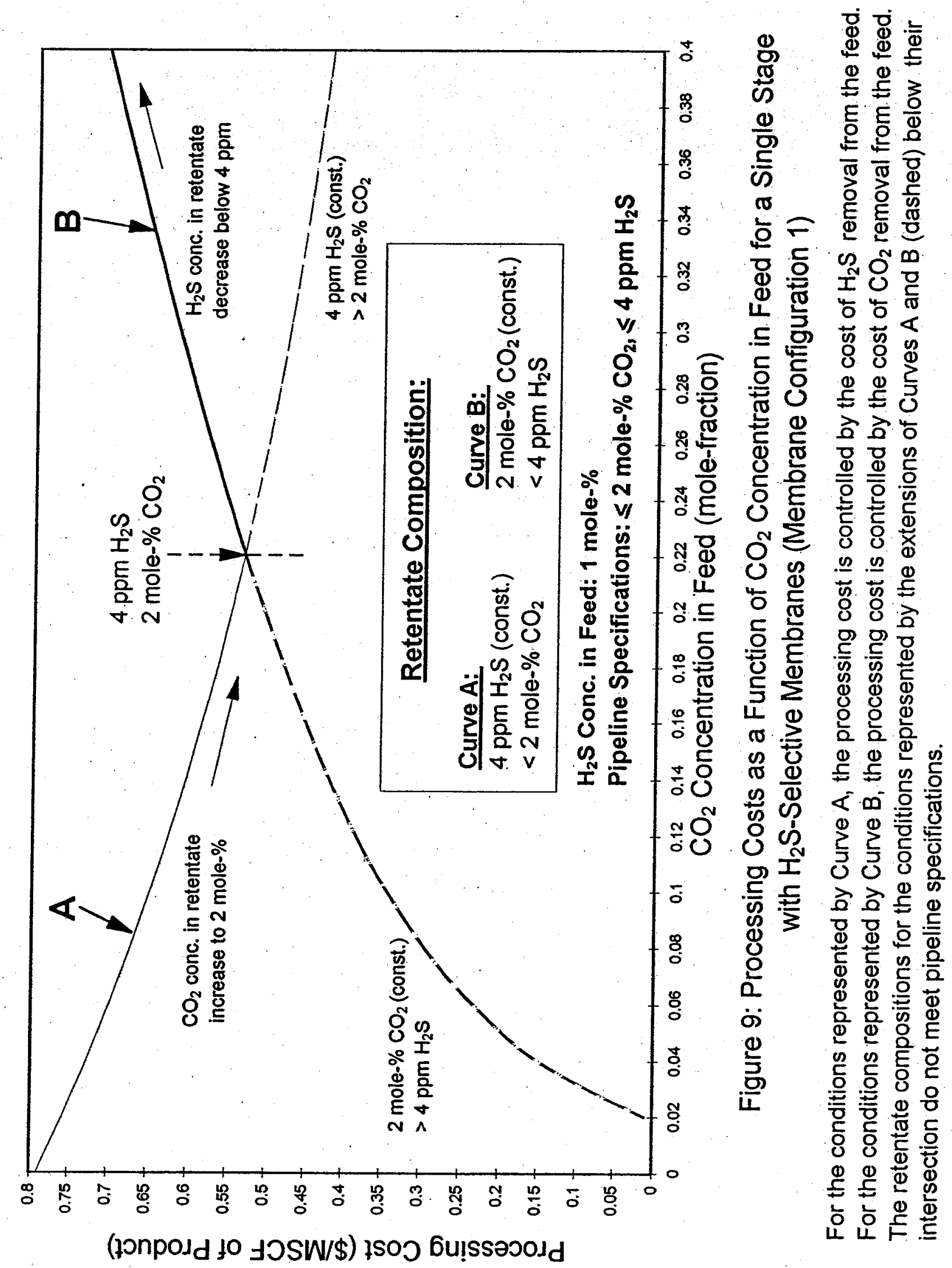


31

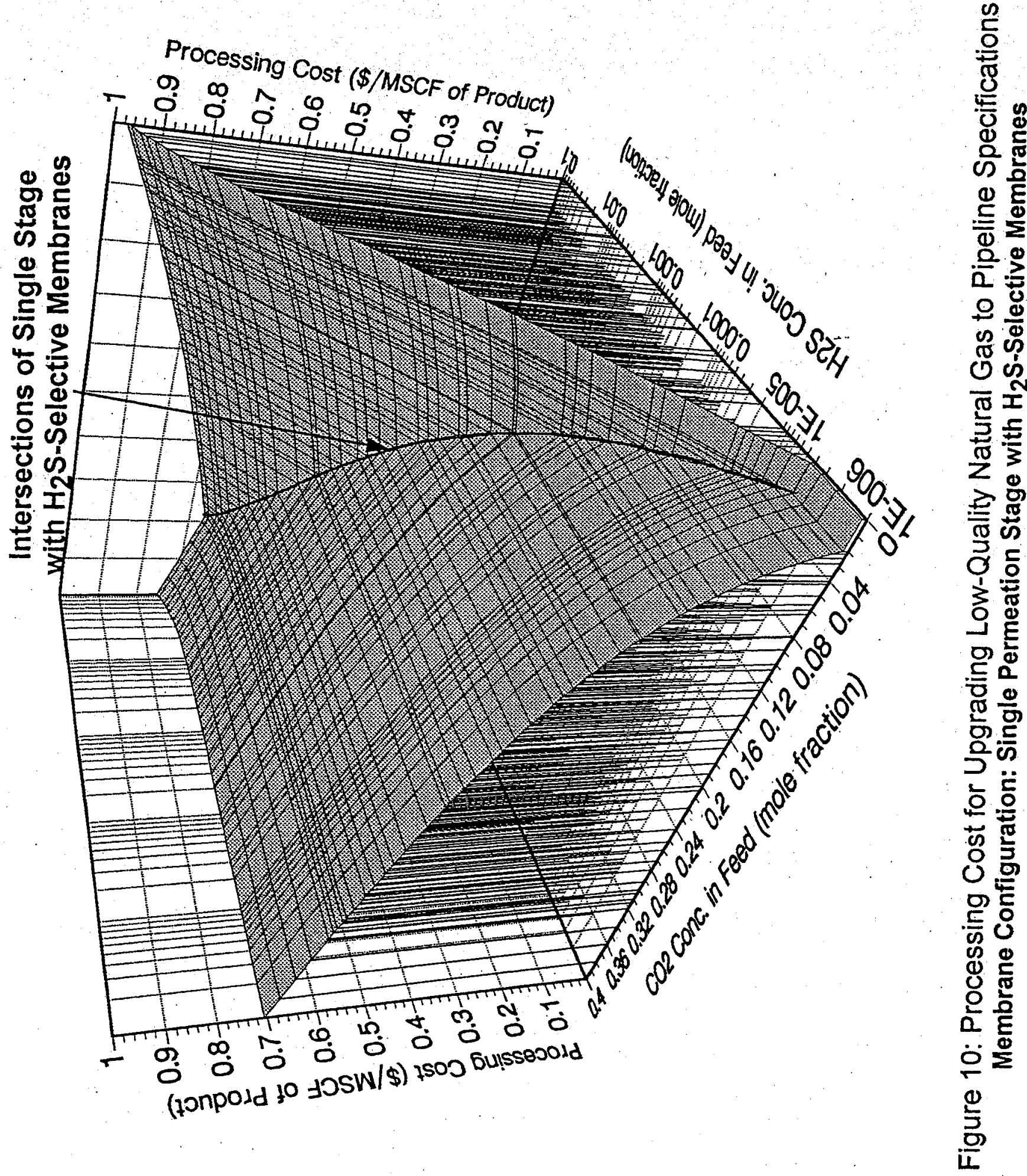




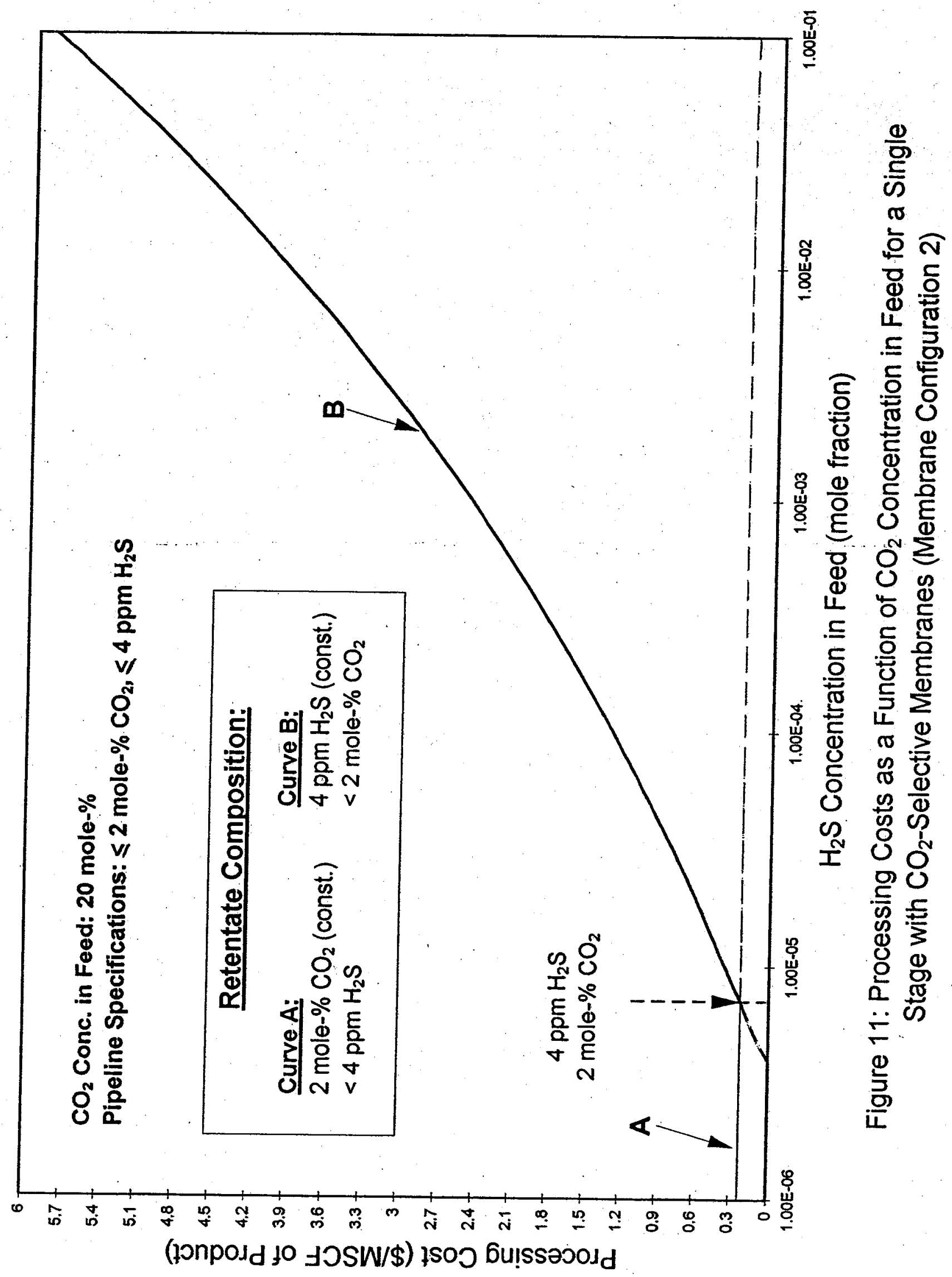




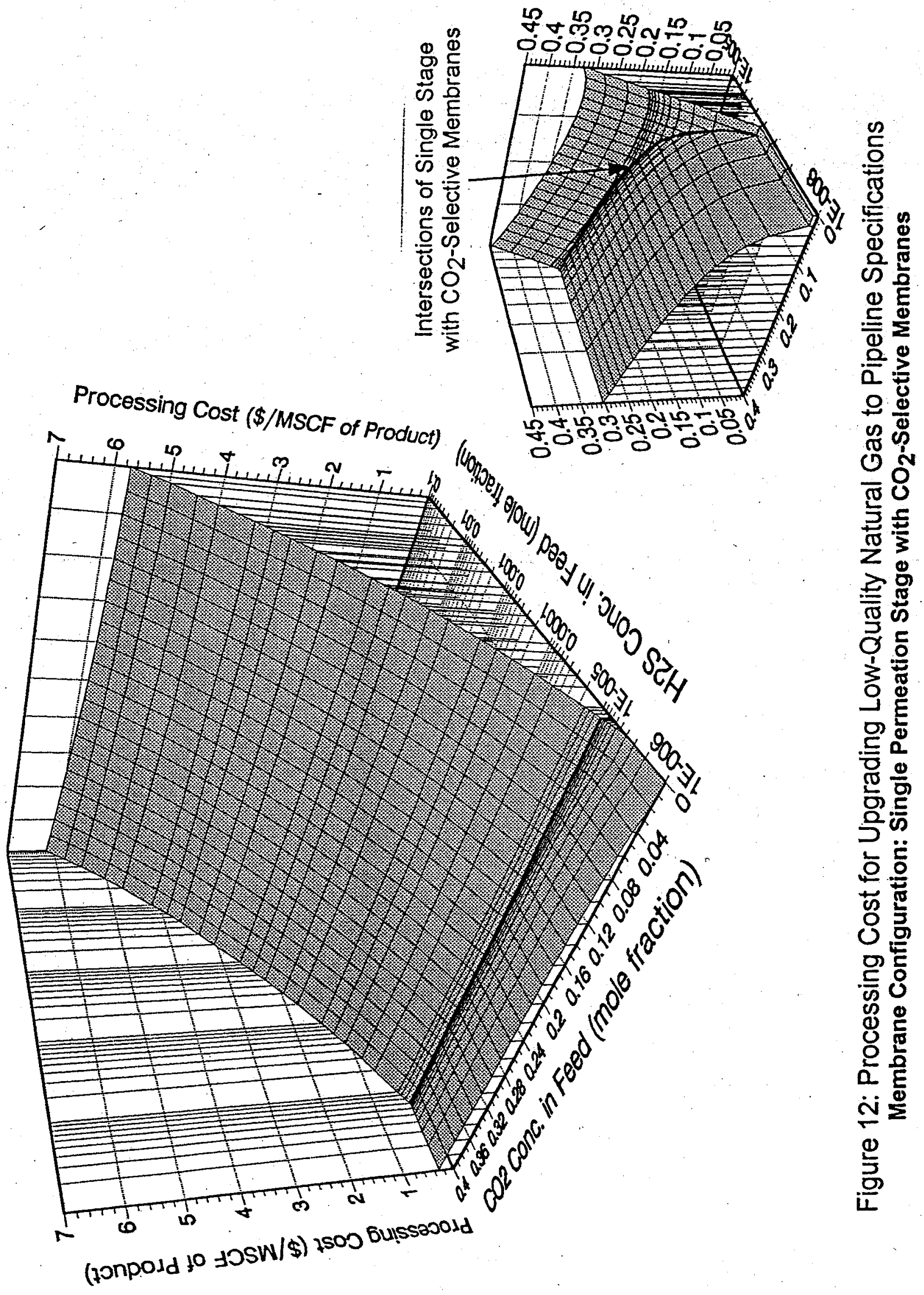




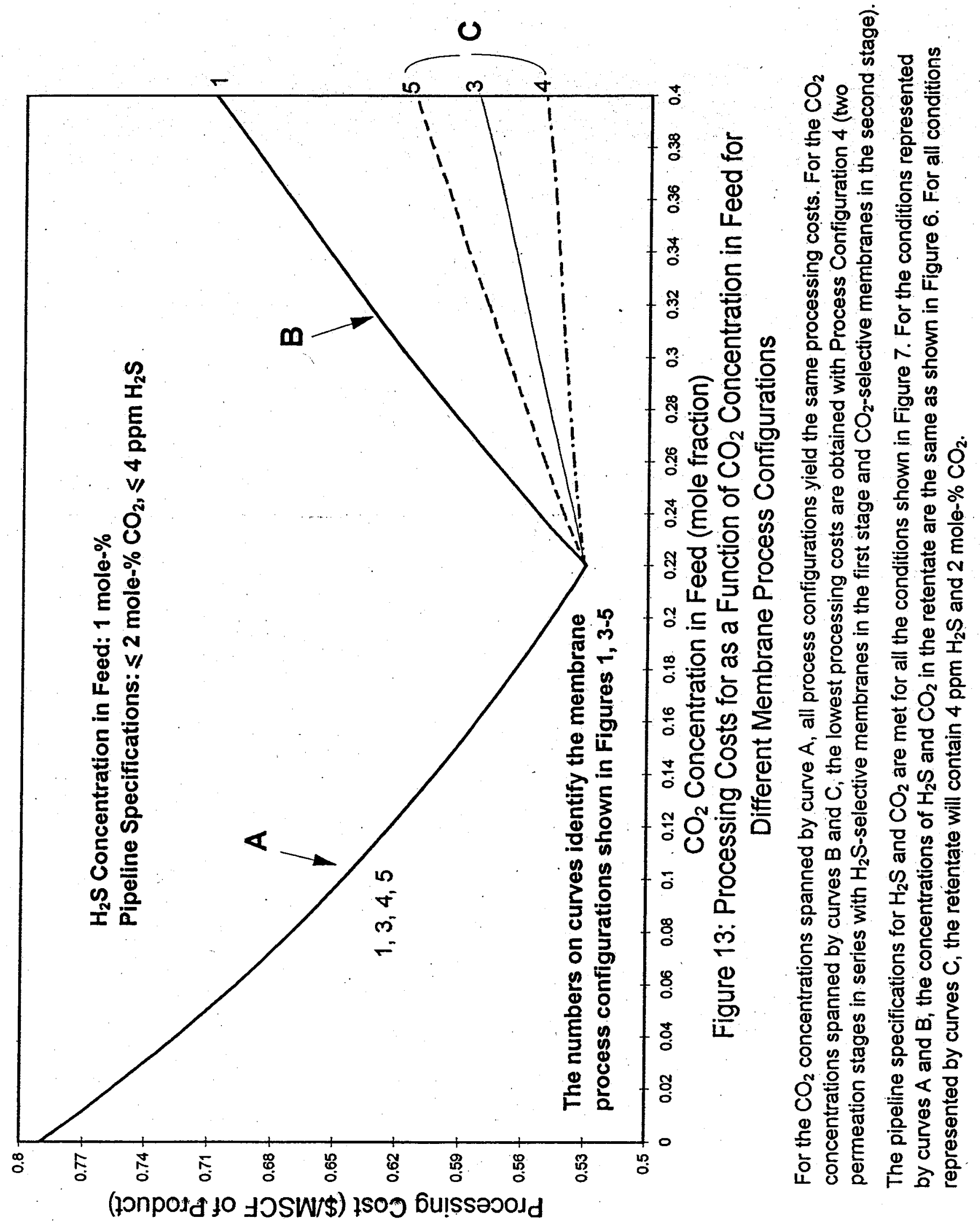




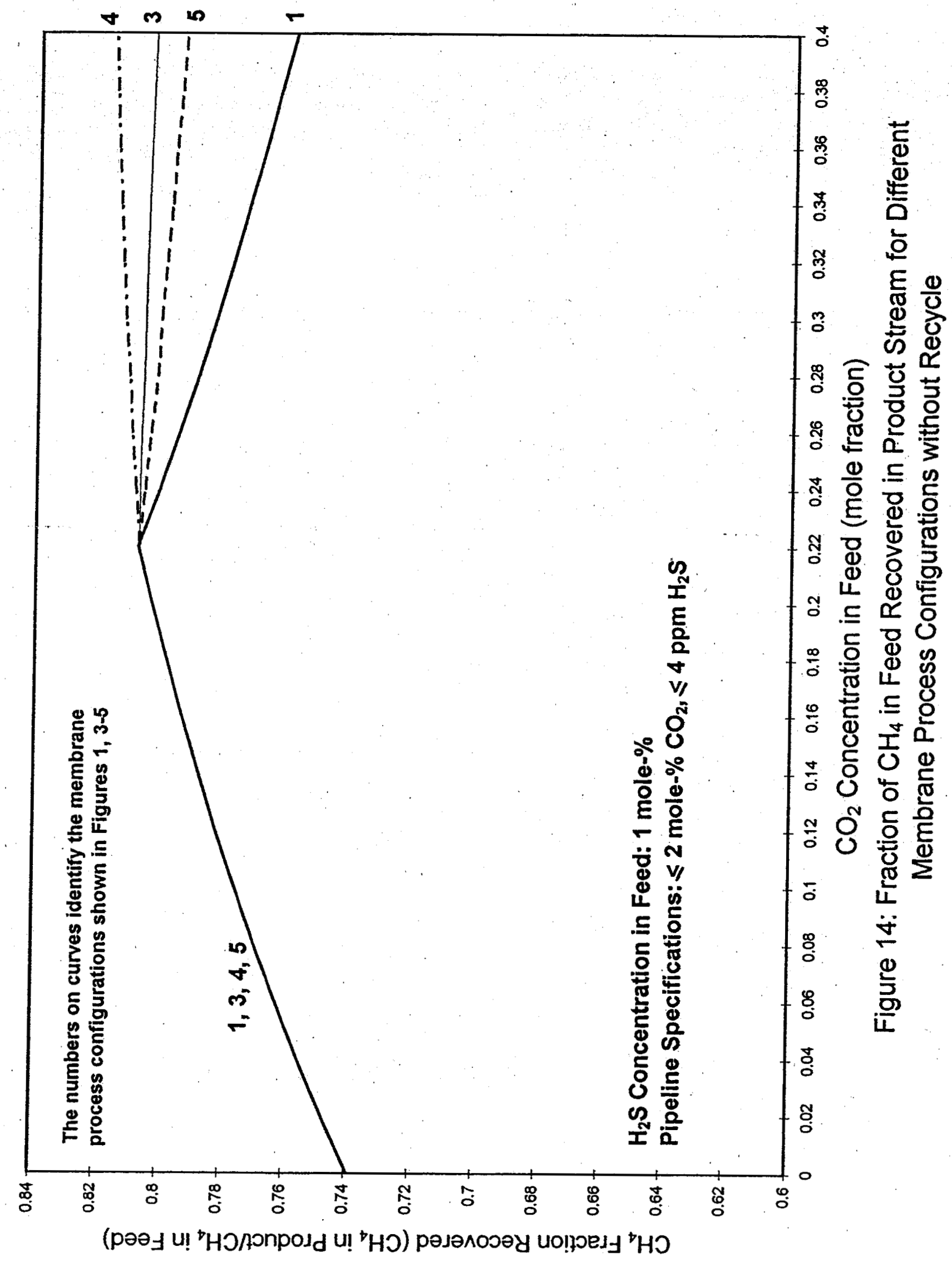




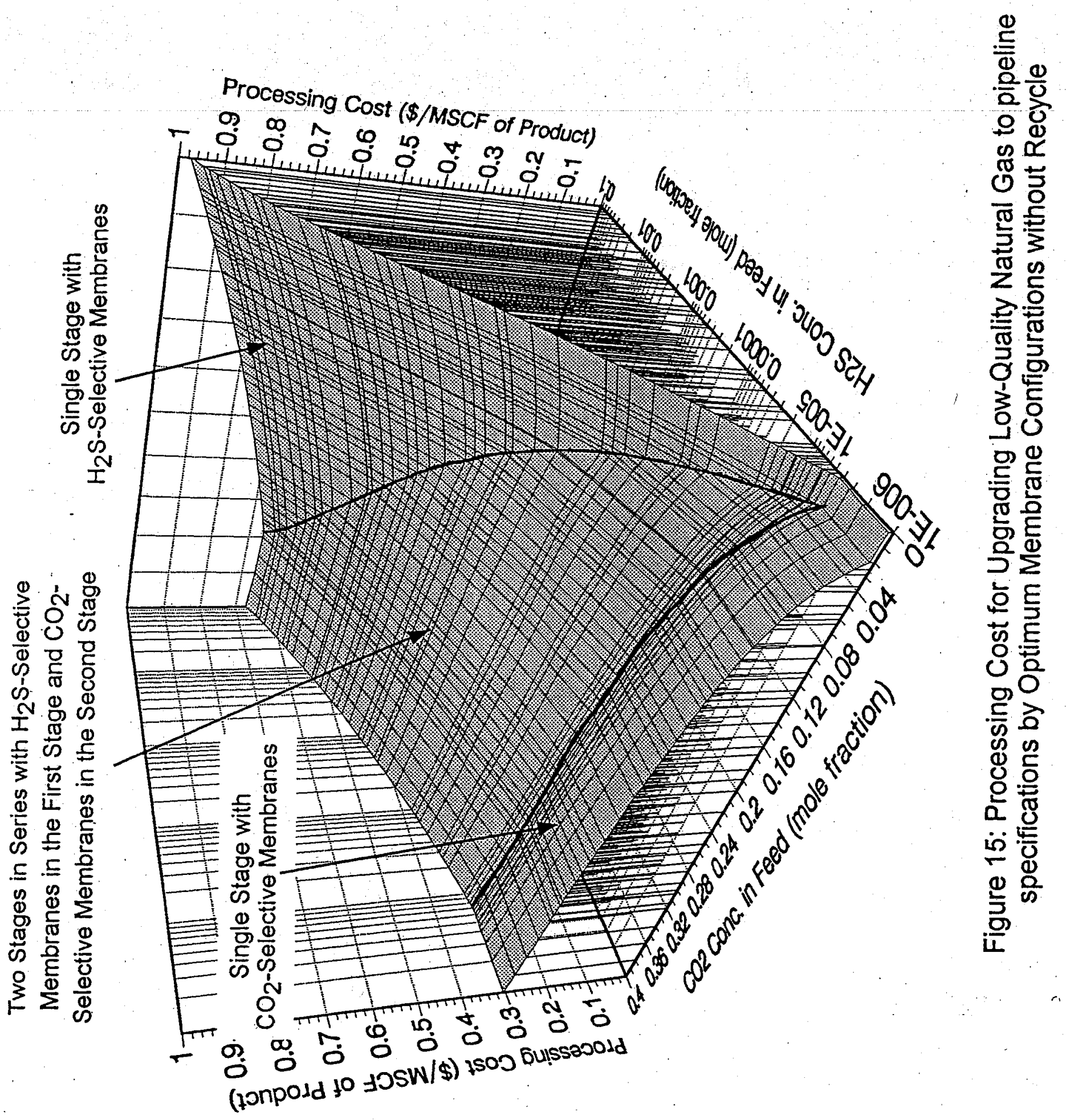




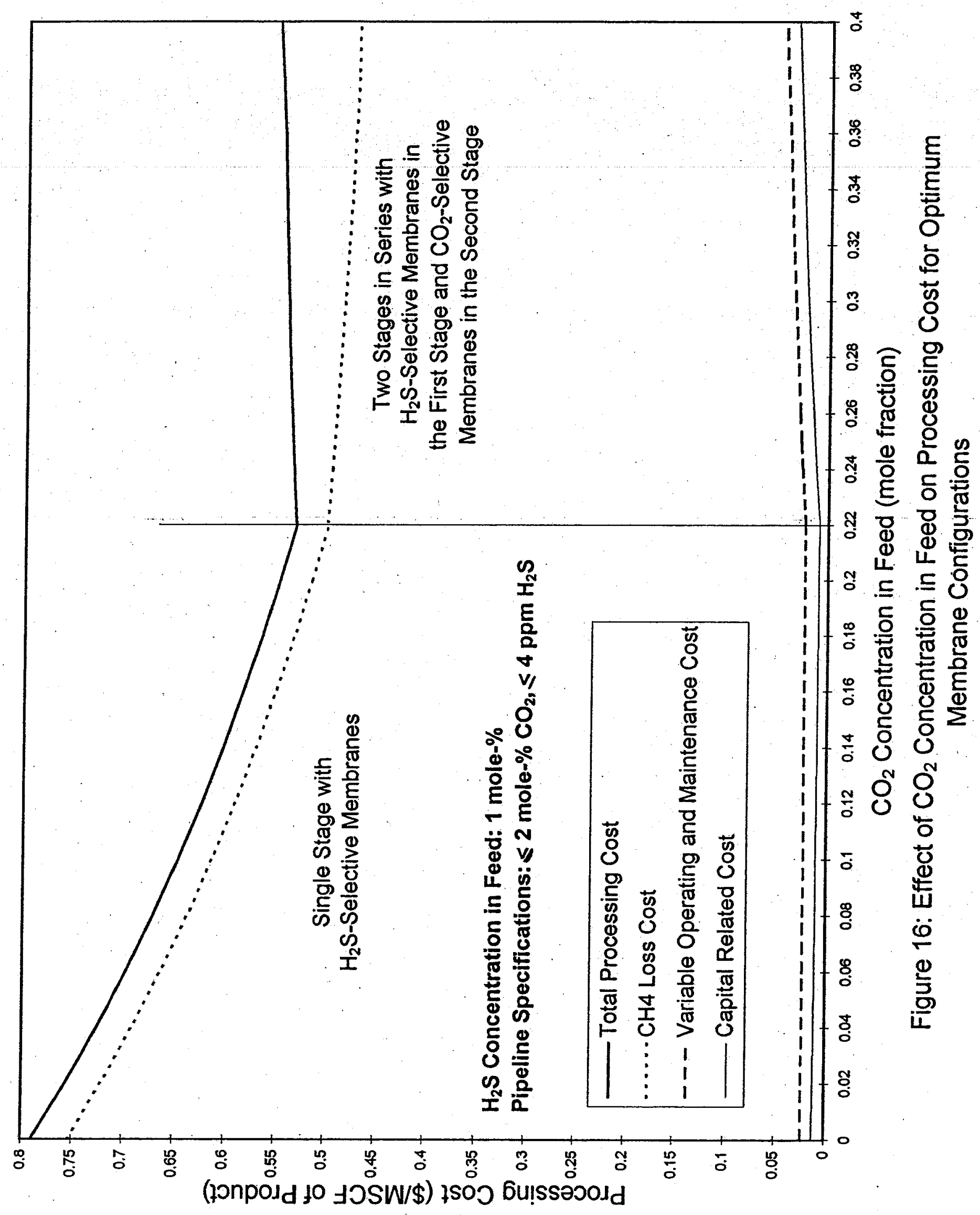




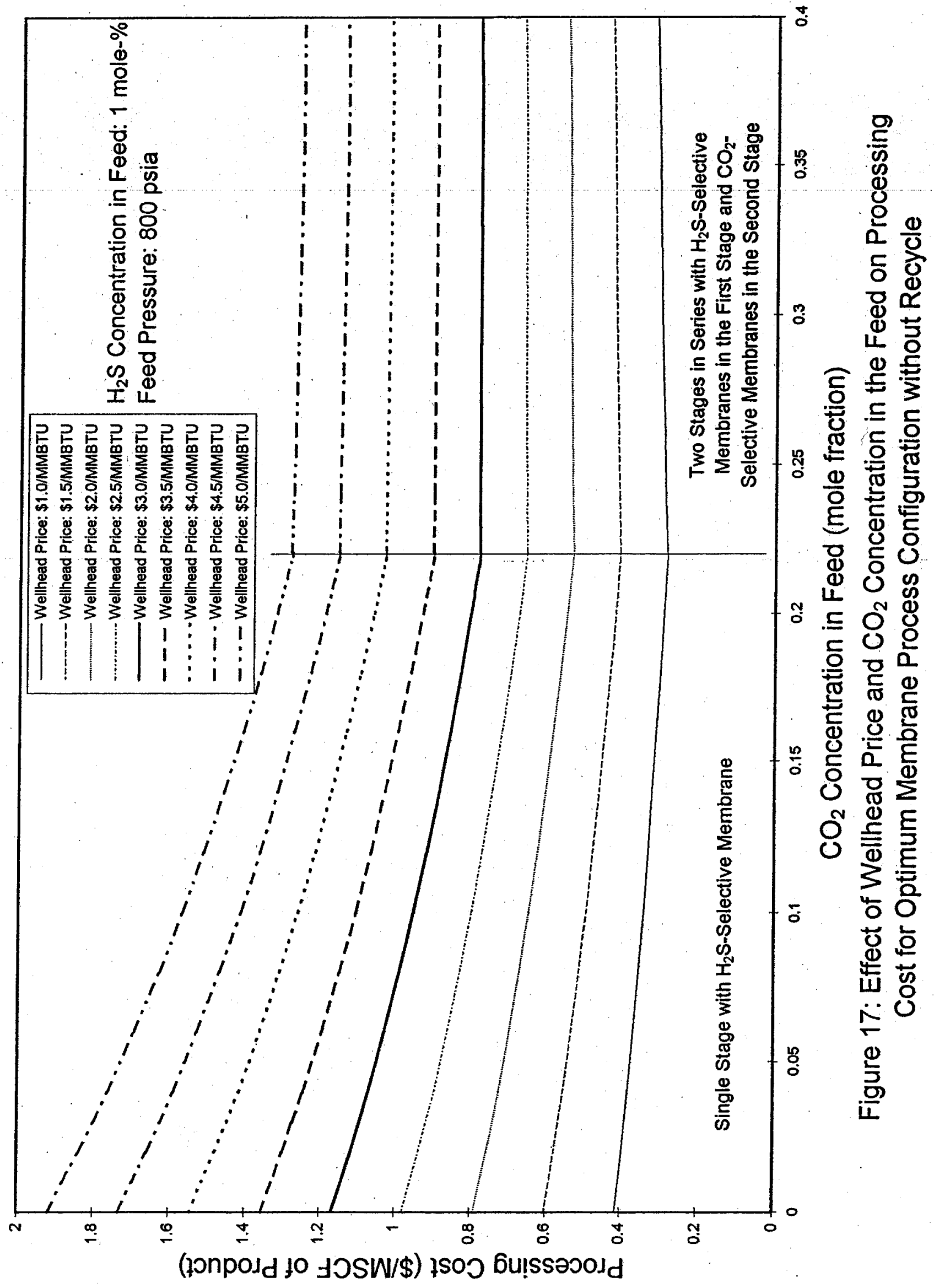




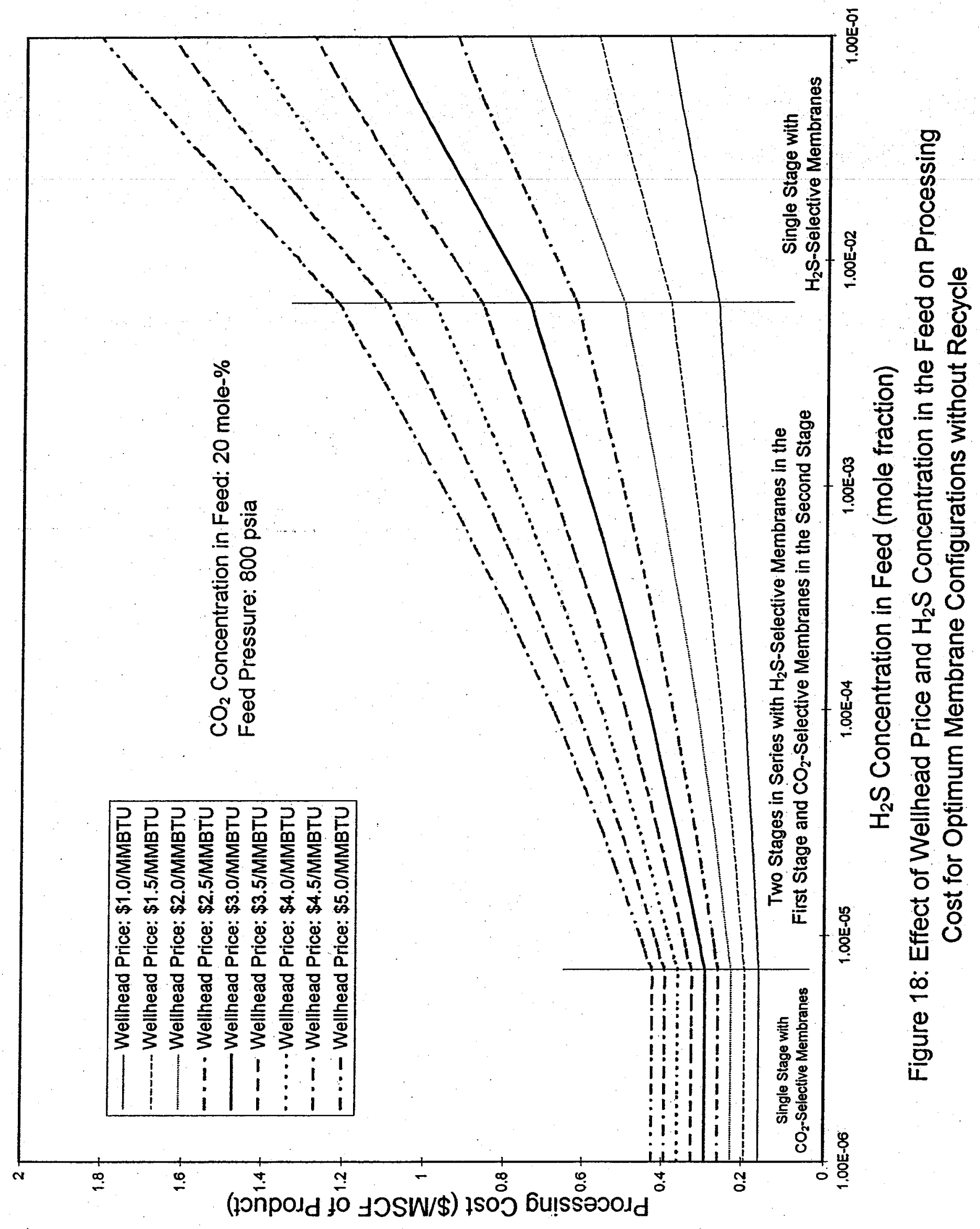









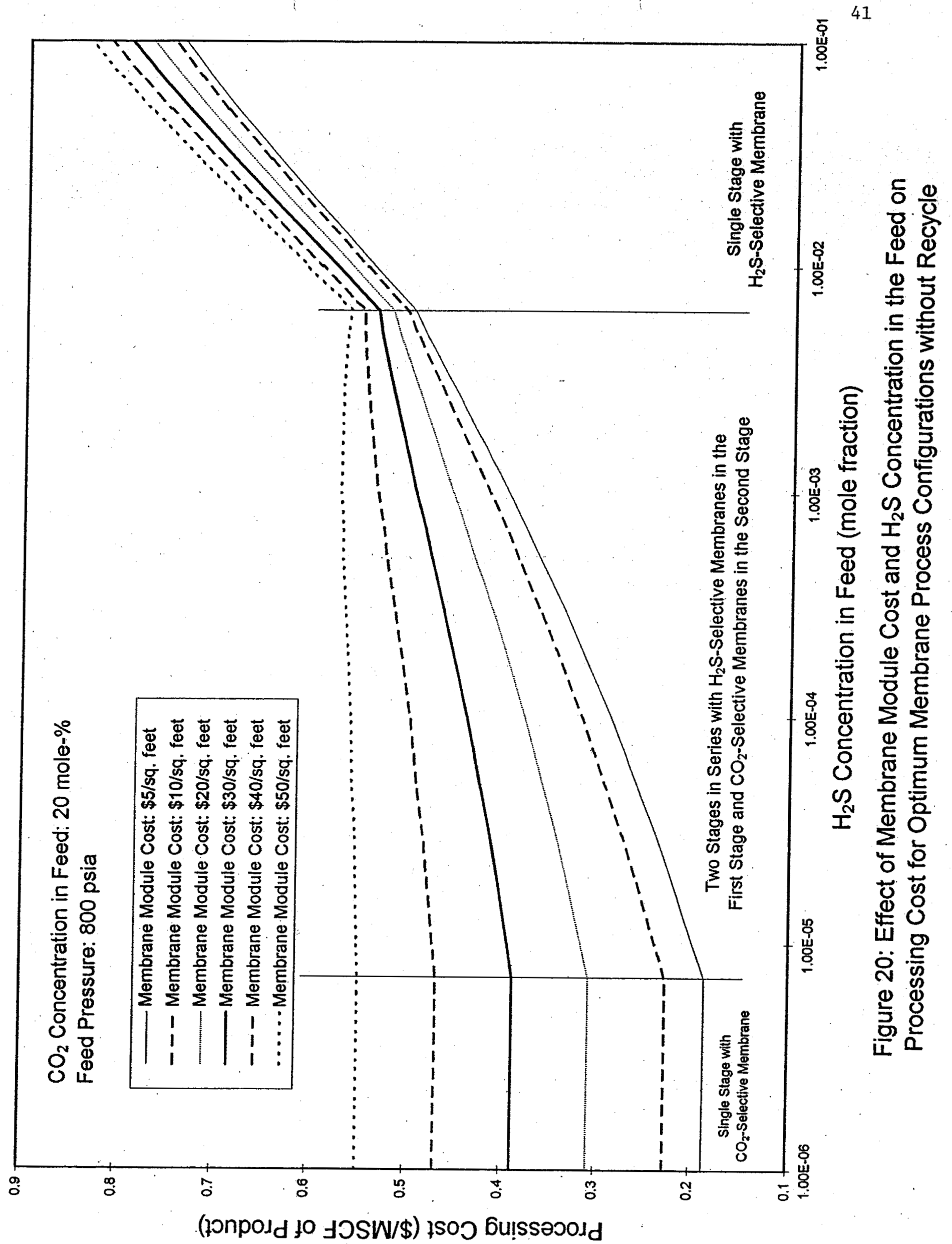




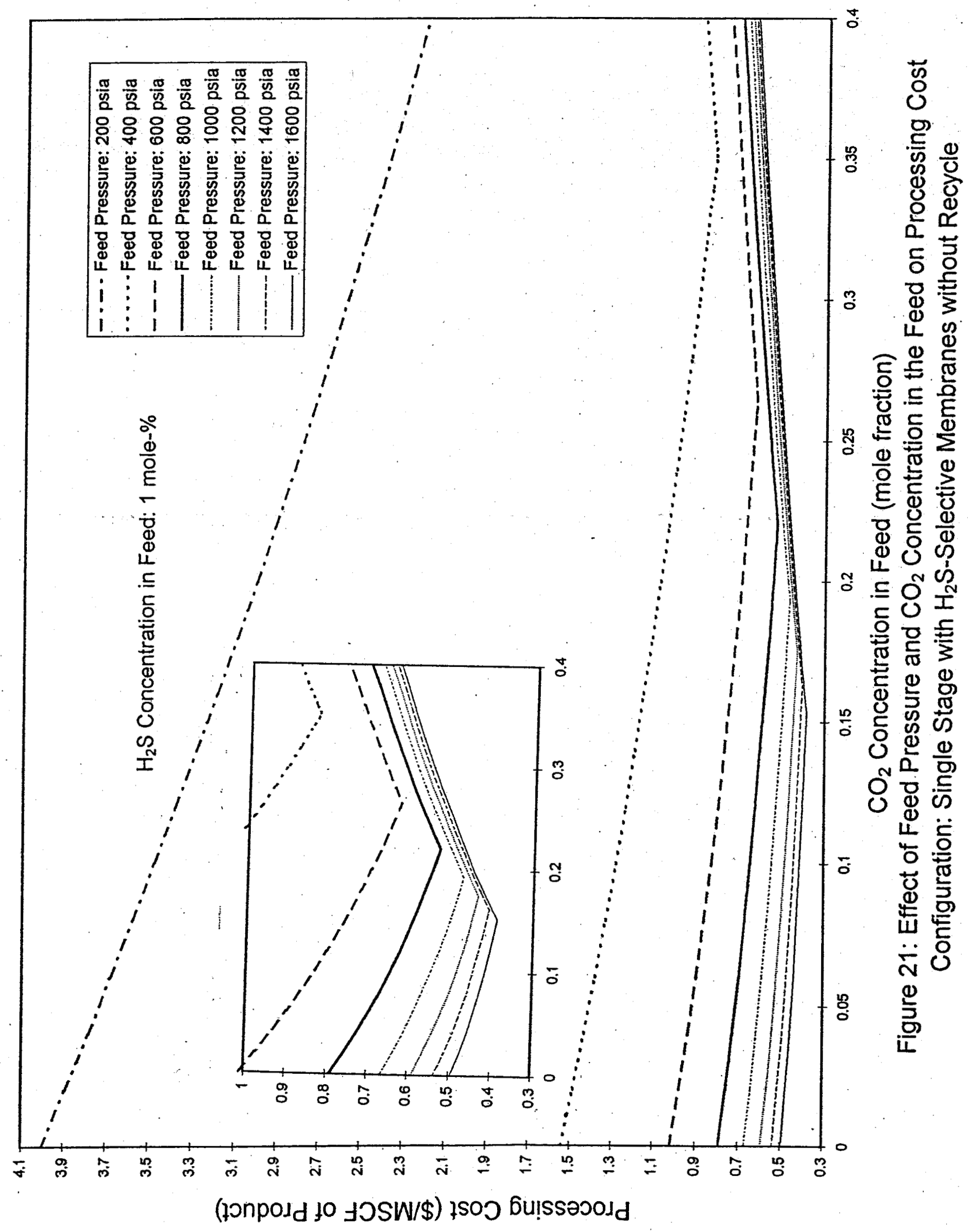




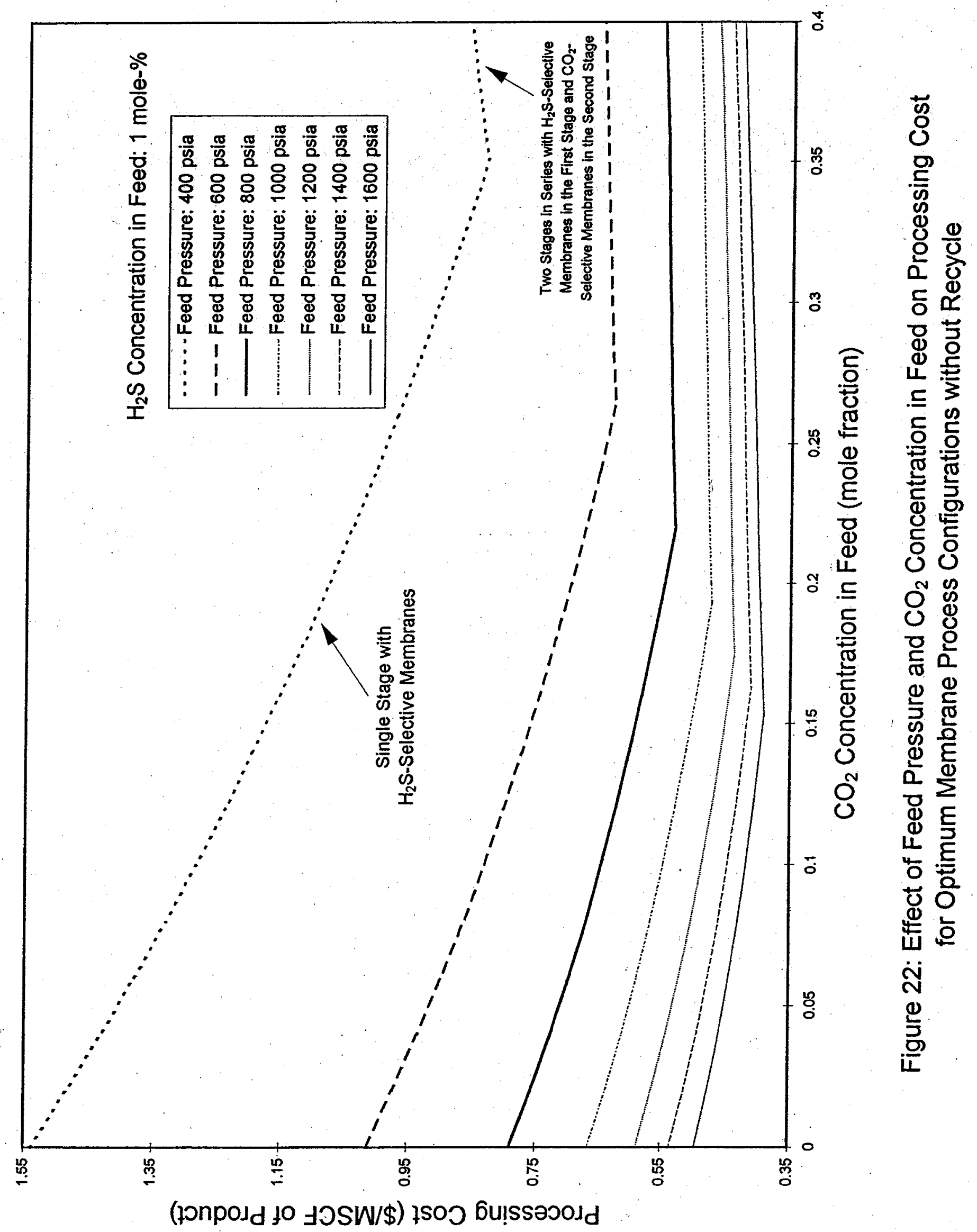




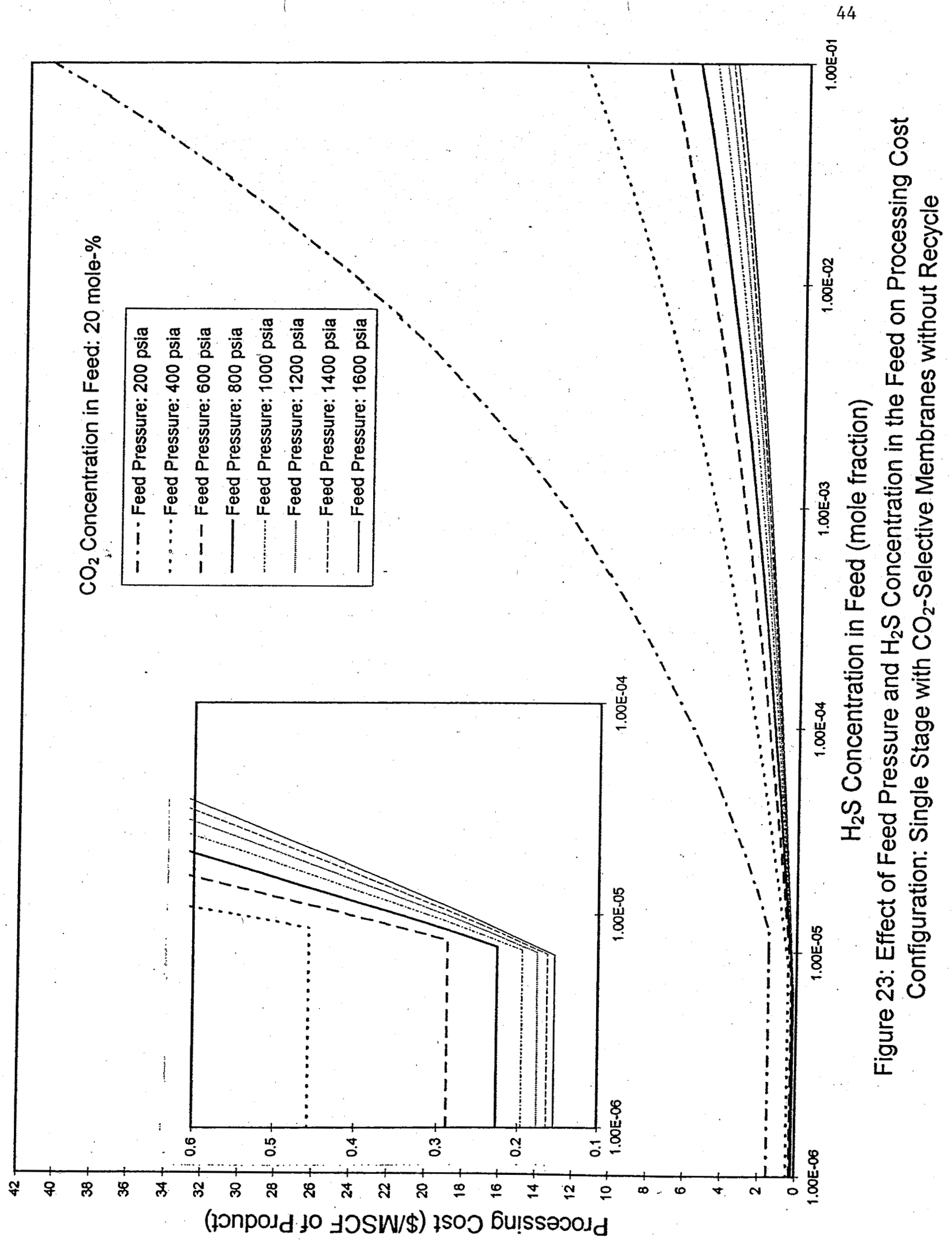




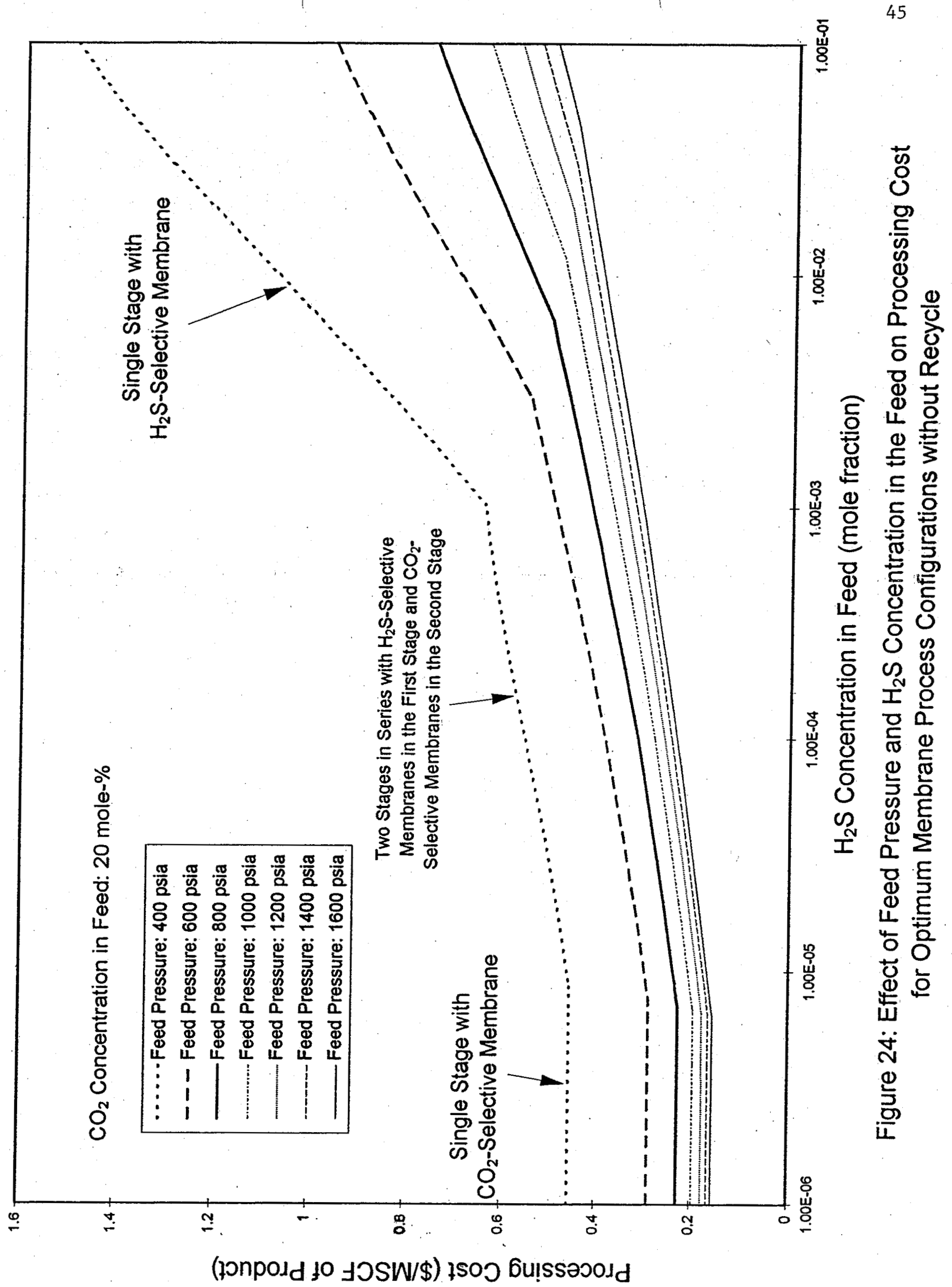




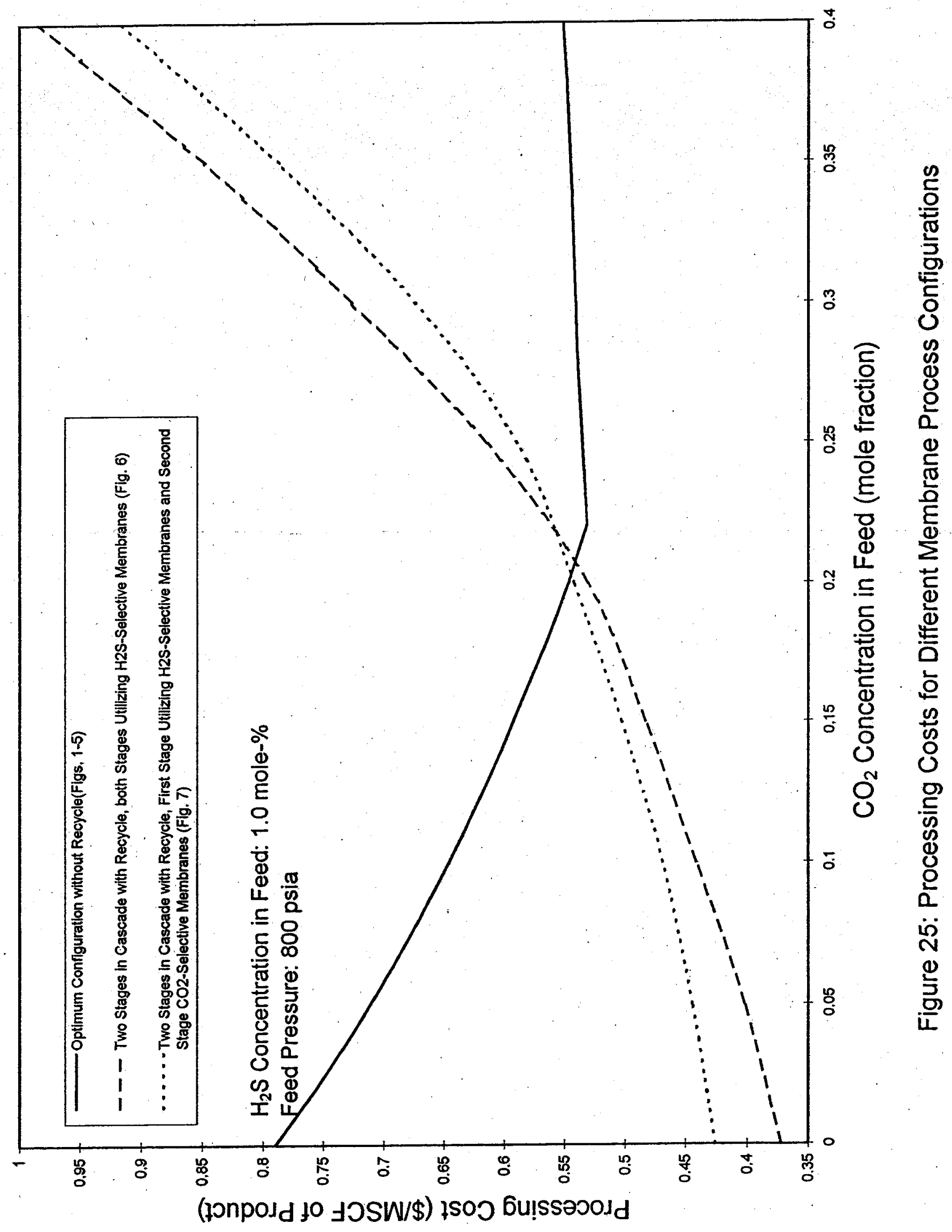




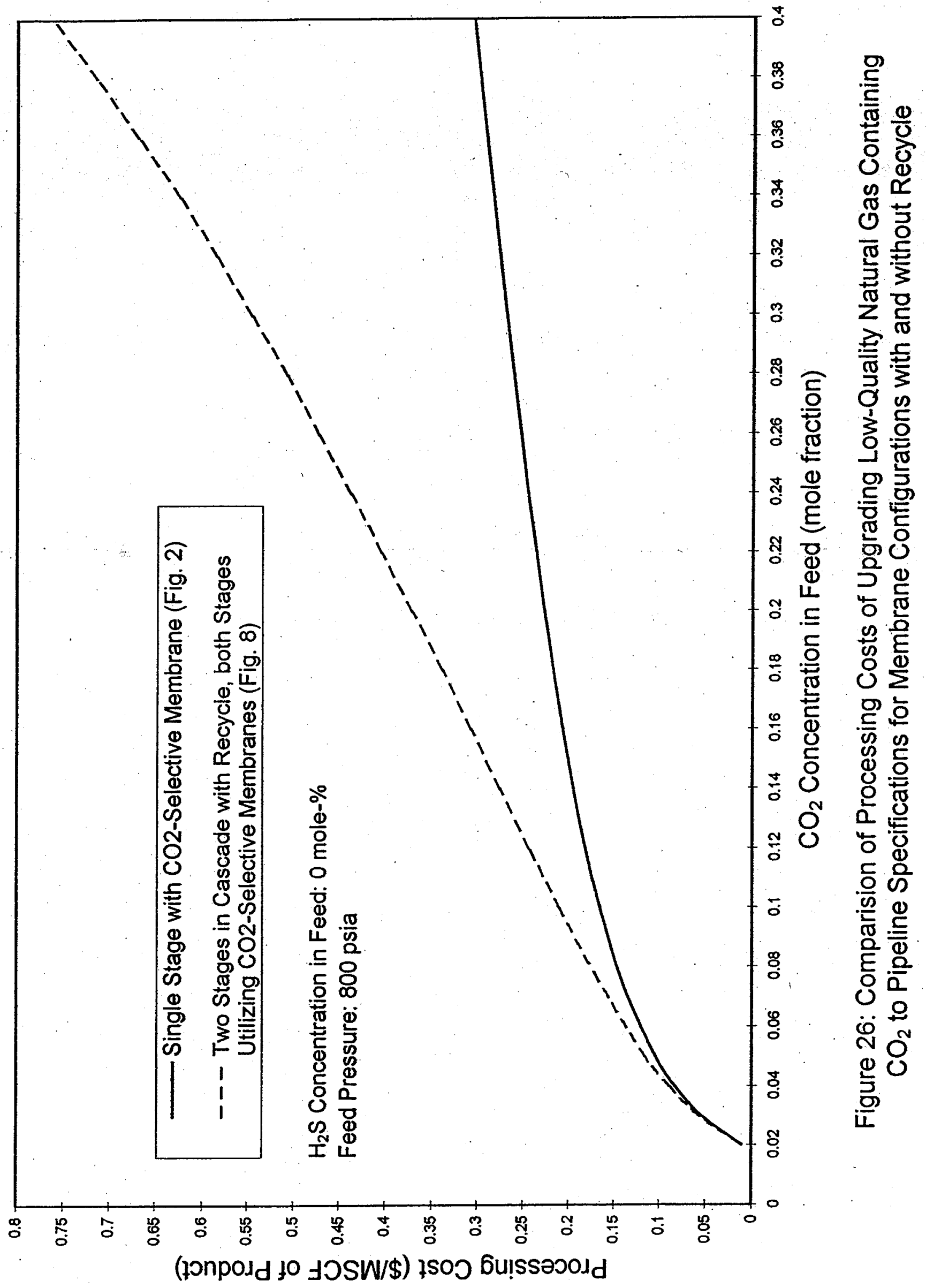




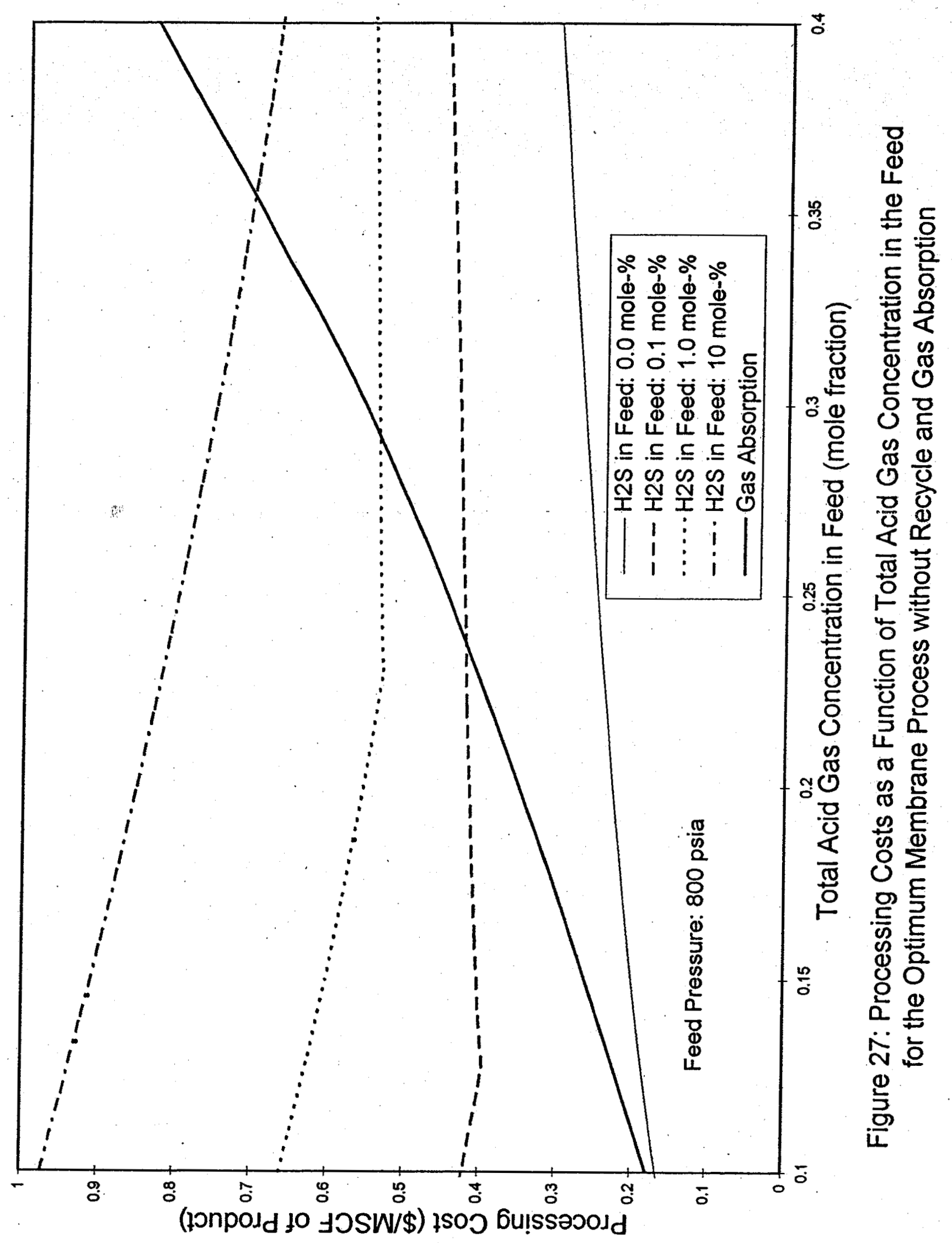

